\title{
Nutrient dynamics and N-anomaly at the SEATS station
}

\author{
George T.F. Wong ${ }^{\mathrm{a}, \mathrm{b}, *}$, Chun-Mao Tseng ${ }^{\mathrm{c}, \mathrm{d}}$, Liang-Saw Wen ${ }^{\mathrm{c}, \mathrm{d}}$, Shi-Wei Chung ${ }^{\mathrm{c}, \mathrm{e}}$ \\ ${ }^{a}$ Research Center for Environmental Changes, Academia Sinica, 128 Academia Road Section 2, Nankang, 115 Taipei, Taiwan, ROC \\ ${ }^{\mathrm{b}}$ Department of Ocean, Earth and Atmospheric Sciences, Old Dominion University, Norfolk, VA 23529, USA \\ ${ }^{\mathrm{c}}$ National Center for Ocean Research, National Taiwan University, P.O. Box 23-13, 10617 Taipei, Taiwan, ROC \\ ${ }^{\mathrm{d}}$ Institute of Oceanography, National Taiwan University, P.O. Box 23-13, 10617 Taipei, Taiwan, ROC \\ ${ }^{\mathrm{e}}$ Tung Fang Institute of Technology, Kaohsiung, Taiwan, ROC
}

Accepted 13 May 2007

Available online 2 August 2007

\begin{abstract}
The distributions of nitrate + nitrite, or $(\mathrm{N}+\mathrm{N})$, and soluble reactive phosphate, or SRP, at the SouthEast Asian Timeseries Study (SEATS) station in the northern South China Sea (SCS) at $18^{\circ} \mathrm{N}$ and $116^{\circ} \mathrm{E}$ were determined in 19 cruises between September 1999 and October 2003. In the deep water below $1500 \mathrm{~m}$, the concentrations of $(\mathrm{N}+\mathrm{N})$ and SRP stayed constant with depth and time at $38.4 \pm 0.3$ and $2.84 \pm 0.03 \mu \mathrm{M}$, respectively. The variability could be accounted for by the analytical uncertainties in the measurements alone. In contrast, variations in the upper water were significantly larger and far exceeded the analytical uncertainties. In the mixed layer, unlike what has been widely reported in other low-latitude waters, there was a distinct seasonal pattern. During most of the year, the concentrations were low and hovered around the detection limits. In the winter, readily detectable concentrations were found as a result of enhanced vertical mixing. In the deep water below $1500 \mathrm{~m}$, the average $(\mathrm{N}+\mathrm{N}) / \mathrm{SRP}$ molar ratio, $13.6 \pm 0.2$, was noticeably lower than the Redfield ratio of 16. The corresponding $\mathrm{N}$-anomaly, $\mathrm{N}^{*}$, was $-4.0 \pm 0.6 \mu \mathrm{M}$. In the upper nutricline, high $(\mathrm{N}+\mathrm{N}) / \mathrm{SRP}$ and $\mathrm{N}^{*}$, even exceeding 16 and $2 \mu \mathrm{M}$, were found. These elevated values are suggestive of the remineralization of nitrogen-rich organic matter in the upper nutricline. Temporally, while there were considerable inter-annual variations, higher $(\mathrm{N}+\mathrm{N}) / \mathrm{SRP}$ and $\mathrm{N}^{*}$ were found mostly between September and April during the period of higher depositional fluxes of atmospheric dust. In the Tropical Water, which was situated within the upper nutricline at $150 \mathrm{~m}$, the average $\mathrm{N}^{*}$ were 1.9 and $-0.3 \mu \mathrm{M}$, and the average $(\mathrm{N}+\mathrm{N}) / \mathrm{SRP}$ were 15.0 and 12.6 in September-April and May-August, respectively. These seasonal patterns suggest that the nitrogen-rich organic matter could have originated from nitrogen fixation, which was enhanced by the availability of iron during seasons of high dust-depositions. A box model calculation indicates that, in the absence of nitrogen fixation, the deficit in combined nitrogen would lead to a rapid escalation in the concentration of SRP in the mixed layer in contradiction to the field observations. If nitrogen fixation is allowed, the deficit in combined nitrogen in the mixed layer could be satisfied and a steady state in $(\mathrm{N}+\mathrm{N})$ and SRP in the mixed layer maintained by supporting $3-13 \%$ of the net primary production by nitrogen fixation.
\end{abstract}

(C) 2007 Elsevier Ltd. All rights reserved.

Keywords: South China Sea; SEATS; Time-series; Nutrients; Nitrogen fixation; JGOFS

\footnotetext{
*Corresponding author. Research Center for Environmental Changes, Academia Sinica, 128 Academia Road Section 2, Nankang, 115 Taipei, Taiwan, ROC.

E-mail address: gtfwong@gate.sinica.edu.tw (G.T.F. Wong).
} 


\section{Introduction}

In low-latitude waters in the tropical and subtropical oceans, insolation is high year-round, the upper water is permanently well stratified, and winter convective overturn induced by seasonal surface cooling is minimal. As a result, the euphotic zone should be characterized by a uniformly high water temperature, low nutrient concentrations, low phytoplankton biomass, and low primary production throughout the year so that consistent regular seasonal variations would be absent (Heinrich, 1962). These general patterns in lowlatitude waters are widely accepted. Observations at the Hawaii Ocean Time-series (HOT) station at $23^{\circ} \mathrm{N}$ have affirmed these patterns to at least as far north as this latitude, although local forcing may lead to irregular minor variations at any time during the year (Karl et al., 1996). Nonetheless, while the SouthEast Asian Time-series Study (SEATS) station is located in the tropical waters in the northern South China Sea (SCS) at $18^{\circ} \mathrm{N}$, at a latitude that is even lower than that at the HOT station, as a result of a unique combination of environmental conditions, the characteristics of its upper water are significantly different from those in other low-latitude areas and these differences have led to patterns in the intraseasonal variations in phyotoplankton biomass that are atypical of low-latitude waters (Tseng et al., 2005).

Chen (2005) surveyed the distributions of phytoplankton biomass and photosynthetically available radiation, and, the variations in new and primary productivity in the northern SCS and concluded that, on the one hand, as in other low-latitude waters, the availability of light is unlikely to be the limiting factor in primary production. On the other hand, the availability of the nutrients is not as limited in the northern SCS as in other low-latitude waters. The confinement of the water in the semienclosed SCS coupled with the large inflow of deep water from the Philippine Sea into the SCS enhance basin-scale upwelling and result in a relatively shallow nutricline at the SEATS station (Chao et al., 1996a; Liu et al., 2002). The top of the nutricline is situated between 50 and $70 \mathrm{~m}$ throughout the year (Tseng et al., 2005). There are two well-defined monsoonal seasons in the SCS: the strong northeast monsoon in the winter and the weaker southwest monsoon in the summer (Tseng et al., 2005). The combined effect of surface cooling and wind-induced mixing in the winter enhances vertical mixing to a sufficient extent that the nutrients in the upper nutricline may be brought into the mixed layer to fuel primary production. As a result, while the phytoplankton biomass and primary production are low for most of the year, a distinct winter maximum can be found regularly (Liu et al., 2002; Chen, 2005; Tseng et al., 2005). These seasonal patterns in phytoplankton biomass and primary production at the SEATS station are distinctly different from the general low-latitude patterns. Superimposed on this regular seasonal pattern, phytoplankton biomass may be elevated episodically when vertical mixing is enhanced by wind associated with tropical cyclones. On average, 14 tropical cyclones traverse the SCS annually (Lin et al., 2003). These wind events also can induce sufficient vertical mixing to bring the nutrients in the upper nutricline to the mixed layer and stimulate primary production. Lin et al. (2003) reported that, in one event in the summer of 2000, after a tropical cyclone of moderate strength, Taiphoon Kai Tak, lingered for 3 days at a location in the northern SCS, the concentration of surface chlorophyll- $a$ was elevated 30 times.

Nitrogen fixation also may occur in the northern SCS and leads to episodic increase in phytoplankton biomass and primary production. Capone et al. (1997) compiled the rates of nitrogen fixation in the world's oceans. While these rates have been reported in only a small number of locations, some of the higher values were found in the SCS. Indeed, the environmental conditions that are conducive to the occurrence of nitrogen fixation: a water temperature exceeding $20^{\circ} \mathrm{C}$, the absence of inorganic combined nitrogen, a stratified water column, and the availability of iron (Karl et al., 1997) can all be met during some periods of time in the year in the northern SCS (Duce and Tinsdale, 1991; Gong et al., 1992; Chao et al., 1996b). Wong et al. (2002) suggested that the distributions of (nitrate + nitrite), or $(\mathrm{N}+\mathrm{N})$, soluble reactive phosphate, or SRP, and, $\delta^{15} \mathrm{~N}$ in $(\mathrm{N}+\mathrm{N})$ at the SEATS station are consistent with the occurrence of nitrogen fixation so that this process potentially may be a significant contributor to the combined nitrogen budget in the northern SCS. Here, we report the temporal variations in the distributions of $(\mathrm{N}+\mathrm{N})$ and $\mathrm{SRP}$, and, further assess their dynamics, especially with respect to the contribution from nitrogen fixation, at the SEATS station. 


\section{Experimental}

\subsection{Station location, sampling chronology and sample collection}

The SEATS station is located at $18^{\circ} \mathrm{N}$ and $116^{\circ} \mathrm{E}$ (Fig. 1) in about $3800 \mathrm{~m}$ of water. It was occupied 19 times between September 1999 and October 2003 in approximately seasonal intervals aboard R/V Ocean Researcher III during cruises 561 (September 17-22) and 585 (November 22-26) in 1999, 600 (January 17-18), 607 (March 12-17), 629 (May 23-26), 644 (July 25-27) and 657 (October 16-21) in 2000, 682 (February 27-March 4), 716 (June 27-July1), 729 (October 2-7) in 2001, and 794 (July 1-3) in 2002, and, aboard R/V Ocean Researcher I during cruises 632 (December 5-11) in 2001, 639 (March 19-April 2), 656 (September 3-4) and 664 (November 11-13) in 2002, and 673 (January 20-21), 674 (March 5-6), 690 (August 7-8) and 696 (October 4-5) in 2003. During each occupation of the station, the distributions of temperature and salinity were recorded with a SeaBird model SBE9/11 conductivity-temperature-depth (CTD) recorder. The distribution of photosynthetically available radiation (PAR) was recorded with a Biospherical model QSR-240 $4 \pi$ quantum scalar irradiance sensor for the estimation of the thickness of the euphotic zone. Discrete water samples were collected to at least $2400 \mathrm{~m}$ with GO-FLO bottles mounted onto a Rosette sampling assembly (General Oceanic). (Samples were available only in the top $200 \mathrm{~m}$ in Cruise 657.)
Between September 1999 and July 2002, subsamples were quick-frozen with liquid nitrogen on board ship and returned to a shore-based laboratory for the determination of nitrite, $(\mathrm{N}+\mathrm{N})$ and SRP. Since then, samples were stored refrigerated at about $4{ }^{\circ} \mathrm{C}$ and were analyzed onboard ship.

\subsection{Analytical method}

Nitrite and $(\mathrm{N}+\mathrm{N})$ were determined by the standard pink azo dye method, which has been adapted for use with a flow injection analyzer (Strickland and Parsons, 1972; Pai et al., 1990). SRP was determined manually with the standard molybdenum blue method (Strickland and Parsons, 1972). The precisions for the determinations of nitrite, $(\mathrm{N}+\mathrm{N})$ and SRP were $\pm 0.03, \pm 0.3$ and $\pm 0.01 \mu \mathrm{M}$, respectively.

\section{Results and discussion}

\subsection{Data quality in nutrient measurements}

The data quality in time-series studies has been assessed traditionally by the consistency of the data in the deep water, where the concentrations should remain constant with time. The concentrations of $(\mathrm{N}+\mathrm{N})$ and SRP in three depth-intervals: $1500-1600 \mathrm{~m}, \quad 2400-2700 \mathrm{~m}$, and $2800-3000 \mathrm{~m}$, which corresponded to $\sigma_{\theta}$ intervals of 27.55-27.61, 27.63-27.65 and 27.64-27.67, during the cruises were examined and the data from 2400 to $2700 \mathrm{~m}$

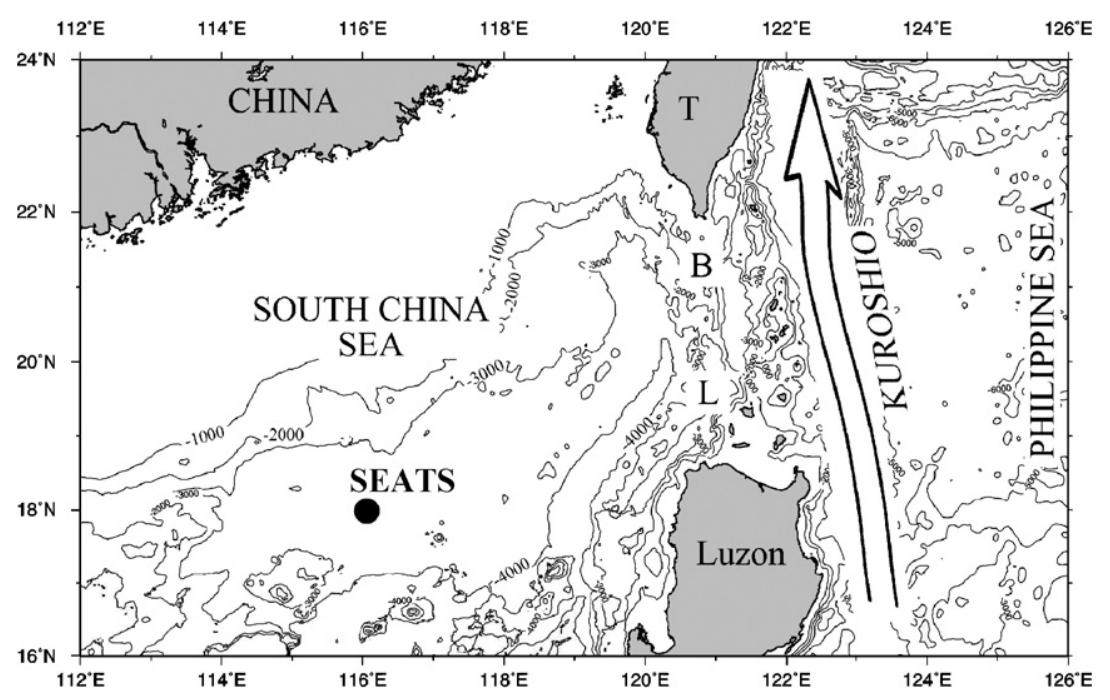

Fig. 1. The location of the SouthEast Asian Time-series Study (SEATS) station in the northern South China Sea. T-Taiwan; B-Bashi Channel; L-Luzon Channel. 


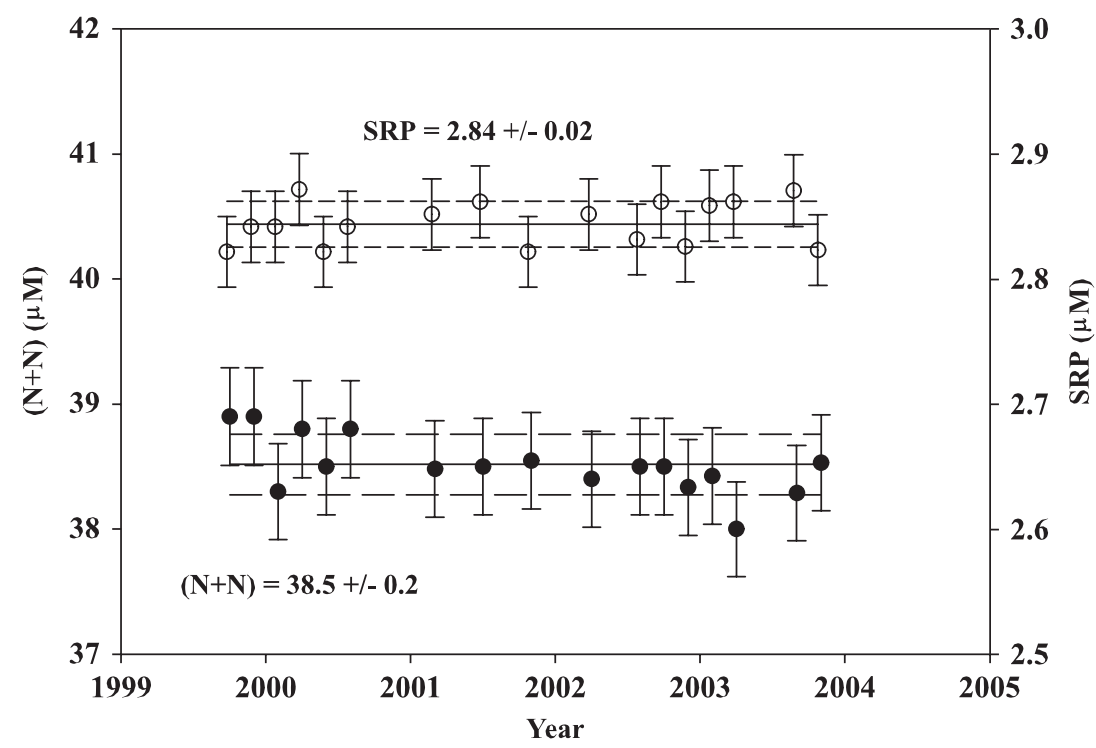

Fig. 2. Temporal variations in the concentrations of $(\mathrm{N}+\mathrm{N})$ and SRP at $2400-2700 \mathrm{~m}$ in the deep water at the SEATS station between September 1999 and October 2003.

are shown in Fig. 2. The results and the corresponding hydrographic characteristics are also summarized in Table 1. The observed temporal and spatial variations in the concentrations of $(\mathrm{N}+\mathrm{N})$ and SRP in these three depth-intervals were similar to the analytical uncertainties in these measurements and thus could be accounted for by this source of uncertainties alone. For the deep water as a whole, the average concentrations of $(\mathrm{N}+\mathrm{N})$ and SRP in all the samples below $1500 \mathrm{~m}$ during the entire sampling period of 4 years were $38.4 \pm 0.3$ and $2.84 \pm 0.03 \mu \mathrm{M}$, respectively. These values agree with those reported previously by Gong et al. (1992) and Chen et al. (2001) to within the combined analytical uncertainties in the studies. The consistent results from the deep water indicate that the quality of the data in the present study was high enough so that temporal variations in the upper water larger than the analytical uncertainties may be attributed to actual changes in environmental conditions.

\subsection{Hydrography at the SEATS station}

The vertical distributions of salinity, $S$, and potential temperature, $\theta$, and the relationship between them at the SEATS stations during the sampling period are shown in Figs. 3 and 4, and they were similar to those reported previously in the northern SCS (Shaw et al., 1996). Salinity and potential temperature were noticeably temporally variable in the surface mixed layer. Below the mixed layer, potential temperature decreased and salinity increased with increasing depth. A salinity-maximum $\left(S>34.6 ; \theta \approx 18^{\circ} \mathrm{C} ; \sigma_{\theta} \approx 25.2\right)$, which represented the Tropical Water, was reached at around $150 \mathrm{~m}$. Below this maximum, salinity decreased with depth to a minimum $\left(S \approx 34.4 ; \theta \approx 8^{\circ} \mathrm{C} ; \sigma_{\theta} \approx 26.7\right)$, which represented the North Pacific Intermediate Water (NPIW), at around $500 \mathrm{~m}$. (The hydrogaphic characteristics of the Tropical Water and the NPIW are listed in Table 1.) The permanent thermocline extended from the base of the mixed layer to about $1500 \mathrm{~m}$. Below $1500 \mathrm{~m}$, potential temperature, salinity and $\sigma_{\theta}$ stayed almost constant at $S=34.6$; $\theta=2{ }^{\circ} \mathrm{C} ; \quad \sigma_{\theta}=27.7$. The $\theta-S$ relationships in individual cruises indicate that the temporal variations were confined to temperatures above $15^{\circ} \mathrm{C}$. The corresponding depth at this temperature was about $200 \mathrm{~m}$. Below $15^{\circ} \mathrm{C}$, the $\theta-S$ relationships were remarkably constant from season to season and from year to year. Thus, seasonal effects on the hydrography at the SEATS station were confined primarily to the top $200 \mathrm{~m}$ of the water column and the core of the Tropical Water was situated at a depth where seasonal effects were still present. Potential temperature and salinity were linearly related to each other below $8^{\circ} \mathrm{C}$. This indicates that there was conservative mixing between the NPIW and the deep/bottom water in the northern SCS.

The distributions of salinity and potential temperature in the top $200 \mathrm{~m}$ of the water column, the average salinity and potential temperature in the 
Table 1

Average composition of Tropical Water, North Pacific Intermediate Water and deep water at different depth-intervals at the SEATS station

\begin{tabular}{|c|c|c|c|c|c|}
\hline & Tropical Water & NPIW & Deep water & & \\
\hline \multicolumn{6}{|l|}{ Depth (m) } \\
\hline Range & $100-150$ & $470-500$ & $1500-1600$ & $2400-2700$ & $2800-3000$ \\
\hline Average & & & $1524 \pm 44$ & $2521 \pm 65$ & $2978 \pm 67$ \\
\hline \multicolumn{6}{|l|}{$\theta\left({ }^{\circ} \mathrm{C}\right)$} \\
\hline Range & $16.2-22.1$ & $7.5-10.2$ & $2.603-2.906$ & $2.159-2.200$ & $2.107-2.140$ \\
\hline Average & $17.6 \pm 1.4$ & $8.4 \pm 0.6$ & $2.74 \pm 0.09$ & $2.18 \pm 0.01$ & $2.12 \pm 0.01$ \\
\hline \multicolumn{6}{|l|}{ Salinity } \\
\hline Range & $34.56-34.72$ & $34.399-34.426$ & $34.573-34.605$ & $34.594-34.624$ & $34.603-34.626$ \\
\hline Average & $34.62 \pm 0.04$ & $34.416 \pm 0.008$ & $34.59 \pm 0.01$ & $34.611 \pm 0.009$ & $34.615 \pm 0.009$ \\
\hline \multicolumn{6}{|l|}{$\sigma_{\theta}$} \\
\hline Range & $24.0-25.4$ & $26.469-26.892$ & $27.556-27.604$ & $27.634-27.657$ & $27.645-27.662$ \\
\hline Average & $25.1 \pm 0.3$ & $26.76 \pm 0.010$ & $27.58 \pm 0.01$ & $27.645 \pm 0.007$ & $27.654 \pm 0.007$ \\
\hline \multicolumn{6}{|c|}{$(\mathrm{N}+\mathrm{N})(\mu \mathrm{M})$} \\
\hline Range & $4.1-16.5$ & $25.6-31.2$ & $37.7-38.6$ & $38.0-38.9$ & $38.0-38.7$ \\
\hline Average & $11.6 \pm 2.8$ & $29.4 \pm 1.5$ & $38.2 \pm 0.3$ & $38.5 \pm 0.2$ & $38.2 \pm 0.2$ \\
\hline \multicolumn{6}{|l|}{$\operatorname{SRP}(\mu \mathrm{M})$} \\
\hline Range & $0.24-1.08$ & $1.80-2.30$ & $2.76-2.92$ & $2.82-2.87$ & $2.82-2.87$ \\
\hline Average & $0.82 \pm 0.19$ & $2.13 \pm 0.14$ & $2.82 \pm 0.05$ & $2.84 \pm 0.02$ & $2.84 \pm 0.02$ \\
\hline \multicolumn{6}{|c|}{$(\mathrm{N}+\mathrm{N}) / \mathrm{P}(\mu \mathrm{M} / \mu \mathrm{M})$} \\
\hline Range & $9.3-17.5$ & $12.7-14.3$ & $13.15-13.90$ & $13.30-13.79$ & $13.29-13.69$ \\
\hline Average & $14.3 \pm 2.2$ & $13.8 \pm 0.5$ & $13.6 \pm 0.2$ & $13.6 \pm 0.3$ & $13.5 \pm 0.1$ \\
\hline \multicolumn{6}{|l|}{$\mathrm{N}^{*}(\mu \mathrm{M})$} \\
\hline Range & -4.4 to 3.8 & -4.45 to -0.60 & -5.41 to -2.85 & -4.82 to -3.32 & -4.86 to -3.62 \\
\hline Average & $1.3 \pm 2.0$ & $-1.8 \pm 0.2$ & $-4.0 \pm 0.7$ & $-4.1 \pm 0.4$ & $-4.3 \pm 0.4$ \\
\hline
\end{tabular}

mixed layer, and, the mixed layer depth (MLD) during the sampling period are shown in Figs. 5 and 6. MLD is defined as the depth above which the density gradient was $\leqslant 0.1 \sigma_{\theta}$ unit $^{-1}$ (Tseng et al., 2005). The values of MLD obtained by this method had been checked against those that were derived from a drop of $0.5^{\circ} \mathrm{C}$ from the sea-surface temperature (Karl and Lukas, 1996). Both methods yielded similar results. Seasonal cycles in potential temperature and salinity in these upper waters were clearly evident. However, the cycles were inversely related to each other. Temperature reached a maximum of $28-30{ }^{\circ} \mathrm{C}$ in the summer and dipped to a minimum of $23-26^{\circ} \mathrm{C}$ in the winter, while salinity dropped to a minimum of $33.1-33.4$ in the summer and rose to a maximum of $33.6-34$ in the winter. Winter cooling was accompanied by a deepening of the MLD. During most of the year, the MLD was shallow and stayed within a narrow range of $20-40 \mathrm{~m}$. During the winter, the MLD deepened significantly and reached $95 \mathrm{~m}$ in the winter of 2002. Tseng et al. (2005) suggested that, individually, surface cooling and wind-induced mixing by the strong northeast monsoon in the winter were insufficient for causing such a significant deepening of the MLD. The phenomenon can be accounted for only by the combined effects of these two processes. This enhanced vertical mixing could have brought the highly saline Tropical Water to the surface layer and led to the elevated salinities in the winter. The average MLD during the entire sampling period, the summers and the winters were $38 \pm 22, \quad 20 \pm 6$ and $67 \pm 26 \mathrm{~m}$, respectively. The larger variability in the average MLD in the winter suggests that the processes that control the MLD in the winter varied inter-annually more significantly.

\subsection{Distributions of dissolved $(N+N), S R P$ and nitrite}

The vertical distributions of $(\mathrm{N}+\mathrm{N})$ and SRP in the entire water column and the distribution of 
nitrite in the upper $200 \mathrm{~m}$ are shown in Figs. 7 and $8 \mathrm{C}$. The upper nutricline, where the gradients in the concentrations of $(\mathrm{N}+\mathrm{N})$ and SRP were the steepest and the remineralization of sinking organic matter was the most intensive, was located between the base of the mixed layer and $500 \mathrm{~m}$. The primary nitrite maximum, where nitrification occurs extensively (Codispoti and Christensen, 1985; Ward, 1987), was located between 50 and $100 \mathrm{~m}$ at the top of the upper nutricline (Fig. 8C). Below $500 \mathrm{~m}$,

(A)

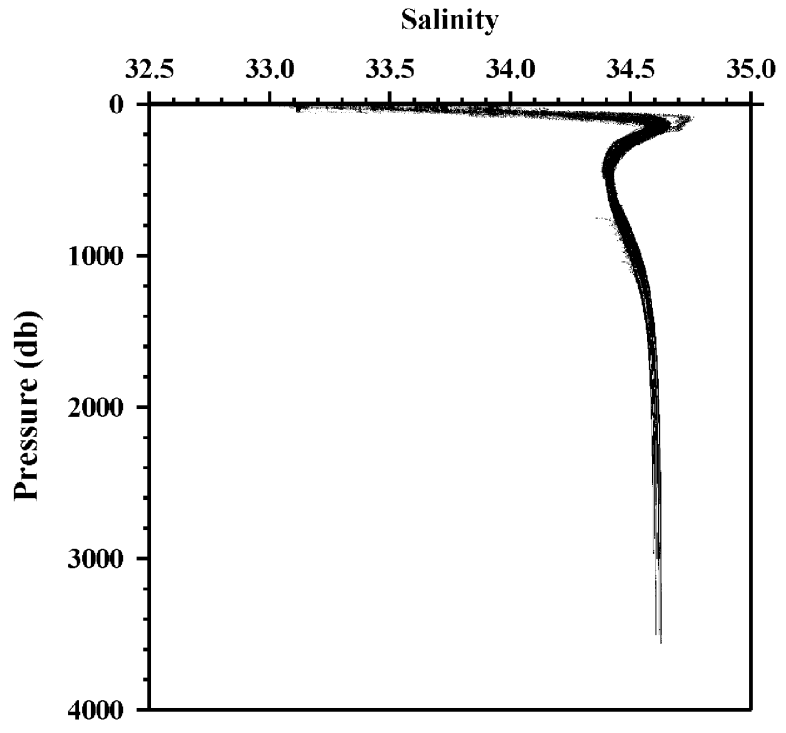

(B)

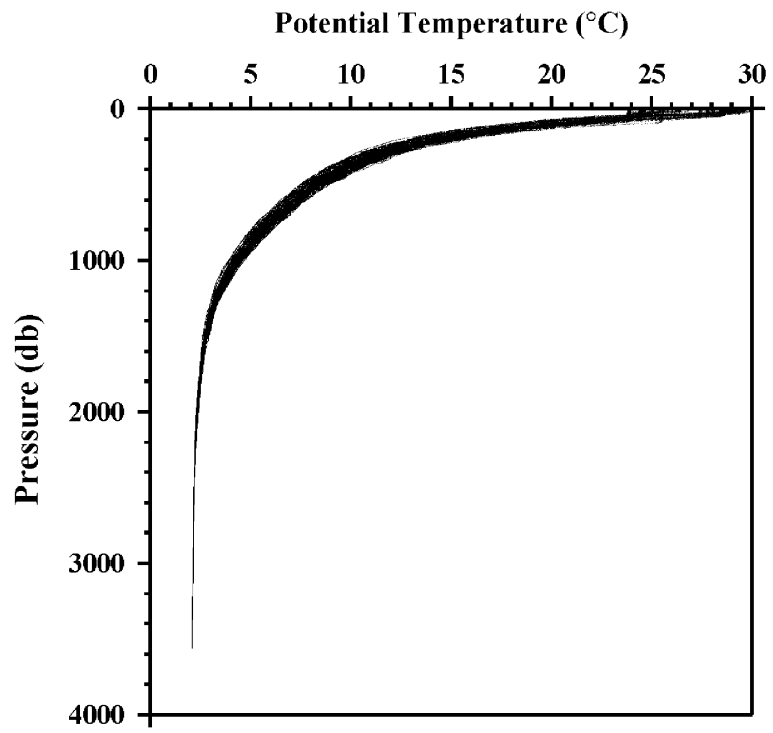

Fig. 3. The vertical distributions of (A) salinity and (B) potential temperature at the SEATS station between September 1999 and October 2003.

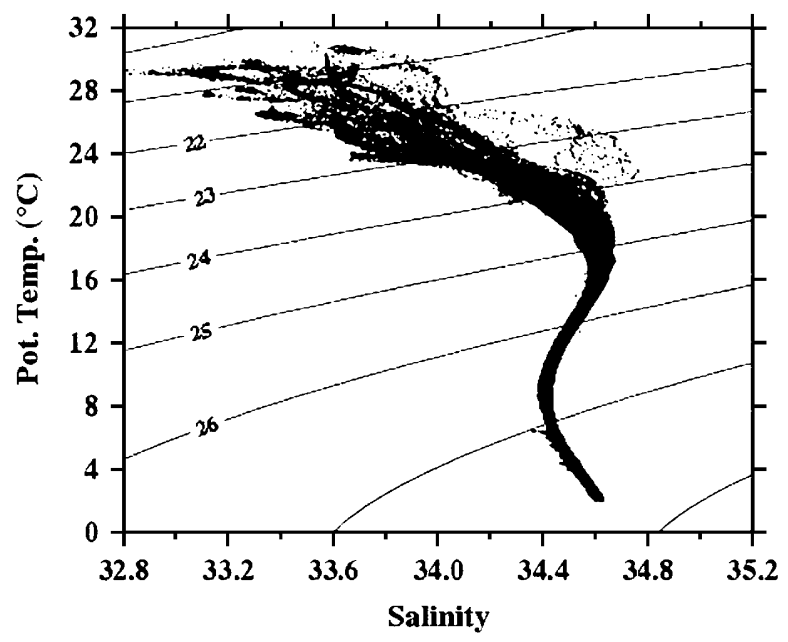

Fig. 4. The relationships between potential temperature and salinity at the SEATS station between September 1999 and October 2003.

the concentrations of $(\mathrm{N}+\mathrm{N})$ and SRP increased more gradually with depth, until they reached an almost constant level below $1500 \mathrm{~m}$ (Fig. 7). While the concentrations of $(\mathrm{N}+\mathrm{N})$ and SRP increased with increasing depth, their temporal variability decreased with increasing depth (Table 1). Thus, the average concentrations of $(\mathrm{N}+\mathrm{N})$ and SRP through the years were $11.6 \pm 2.8$ and $0.82 \pm 0.19 \mu \mathrm{M}$ in the Tropical Water, $29.4 \pm 1.5$ and $2.13 \pm 0.14 \mu \mathrm{M}$ in the NPIW and $38.4 \pm 0.3$ and $2.84 \pm 0.03 \mu \mathrm{M}$ in waters below $1500 \mathrm{~m}$. In the upper nutricline at about $100 \mathrm{~m}$, the variations in the concentrations of $(\mathrm{N}+\mathrm{N})$ and SRP exceeded 5 and $0.5 \mu \mathrm{M}$ (Fig. 7). These variabilities in the shallower water far exceeded what might be attributed to analytical uncertainties, and indicate real and significant temporal variations in the nutrient dynamics at these depths.

The distributions of $(\mathrm{N}+\mathrm{N}), \mathrm{SRP}$ and nitrite in the upper $200 \mathrm{~m}$ of the water column, and, the averaged concentrations of $(\mathrm{N}+\mathrm{N})$ and SRP in the mixed layer are shown in Figs. 8 and 9. The euphotic zone depth (EZD) and the depth at the top of the nutricline (TND) are shown in Fig. 6B. EZD is the depth at which the PAR had been reduced to $1 \%$ of the surface value. TND is defined as the depth corresponding to the temperature at the $x$-intercept in a linear regression analysis of the concentration of $(\mathrm{N}+\mathrm{N})$ in the upper nutricline against potential temperature. There was a distinct seasonal pattern in the distributions of $(\mathrm{N}+\mathrm{N})$ and SRP in the mixed layer. The isopleths of $(\mathrm{N}+\mathrm{N})$ and 
(A)

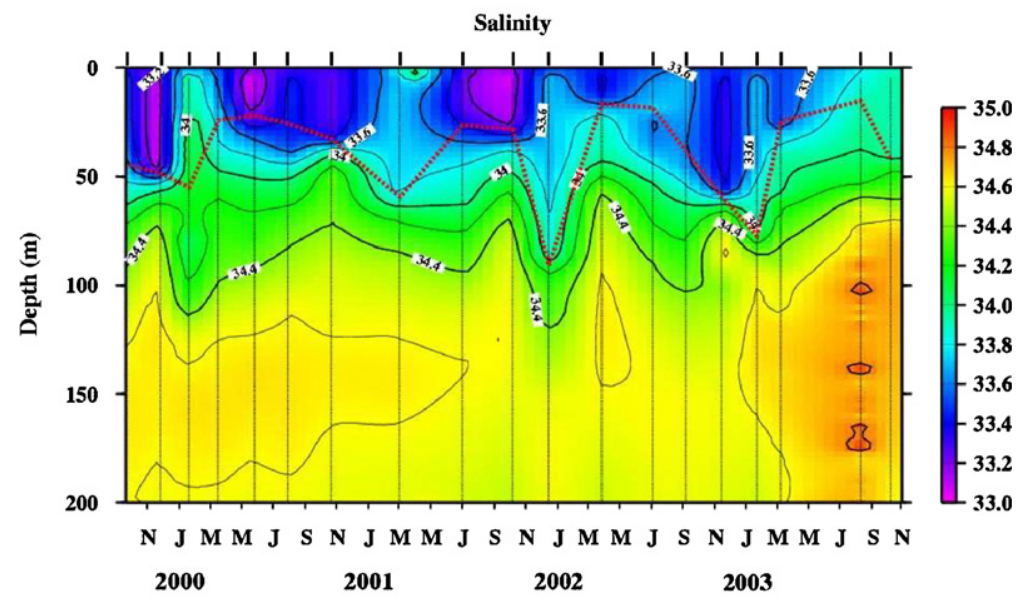

(B)

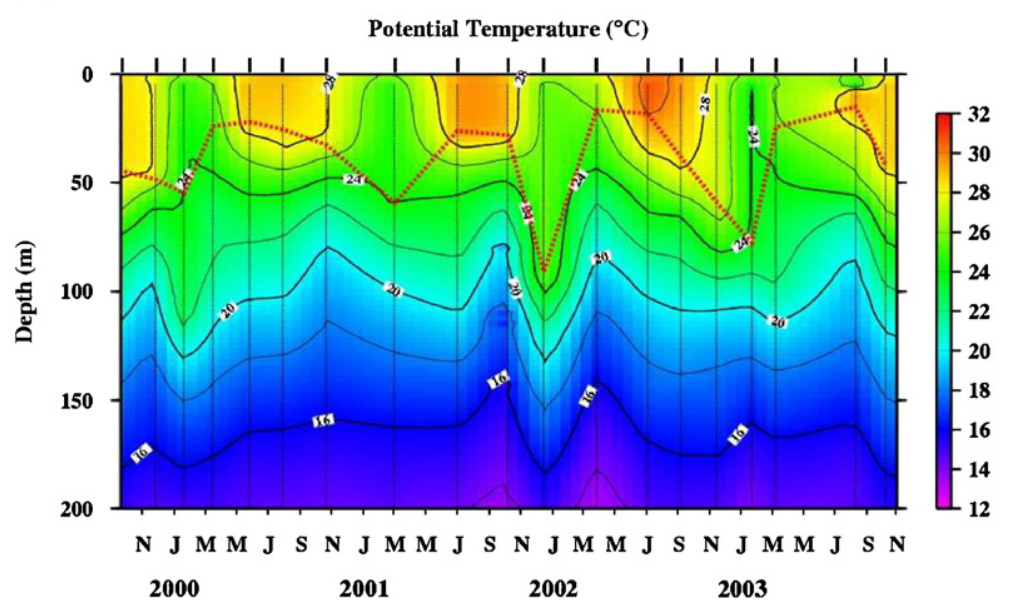

Fig. 5. Temporal variations in (A) salinity and (B) potential temperature in the top $200 \mathrm{~m}$ at the SEATS station between September 1999 and October 2003. The vertical lines represent the times of sampling. The MLD is indicated by the heavy dotted line.

SRP (Fig. 8A and B) were elevated to shallower depths during the winter. Thus, while the concentrations of $(\mathrm{N}+\mathrm{N})$ and SRP were low for most of the year and hovered around their respective detection limits of 0.03 and $0.01 \mu \mathrm{M}$ in the summer, low but readily detectable concentrations, $0.1-0.4 \mu \mathrm{M}$ of $(\mathrm{N}+\mathrm{N})$ and $0.02-0.06 \mu \mathrm{M}$ of SRP, were found in the winter (Fig. 9). These higher concentrations were likely to be the result of the enhanced vertical mixing and the thickening of the mixed layer, which also led to the higher salinity in the mixed layer, in the winter (Tseng et al., 2005). The layer of nitrite-rich water in the primary nitrite maximum, with concentrations above $0.1 \mu \mathrm{M}$, was thicker and also extended to shallower depths in most winters (Fig. 8C). There was also an indication that the maximum concentration of nitrite could have been higher in the winter.
These phenomena could have been the result of the higher primary production (Tseng et al., 2005) and, thus, a more extensive nitrification in the upper nutricline in this season. However, it should be noted that the sample spacing used in this study was rather coarse and was not ideal for mapping this thin nitrite maximum. This sampling scheme could introduce distortions into the details in the distribution of nitrite in this layer of water.

During the sampling period, in contrast to the large seasonal variations in MLD, both the EZD and TND stayed within narrow depth-ranges of $75-95 \mathrm{~m}$, averaging $84 \pm 6 \mathrm{~m}$, and $40-60 \mathrm{~m}$, averaging $54 \pm 8 \mathrm{~m}$, respectively. Relative to the EZD, the TND was consistently shallower. Thus, the availability of nutrients had become the limiting factor of photosynthetic activities before the 
(A)

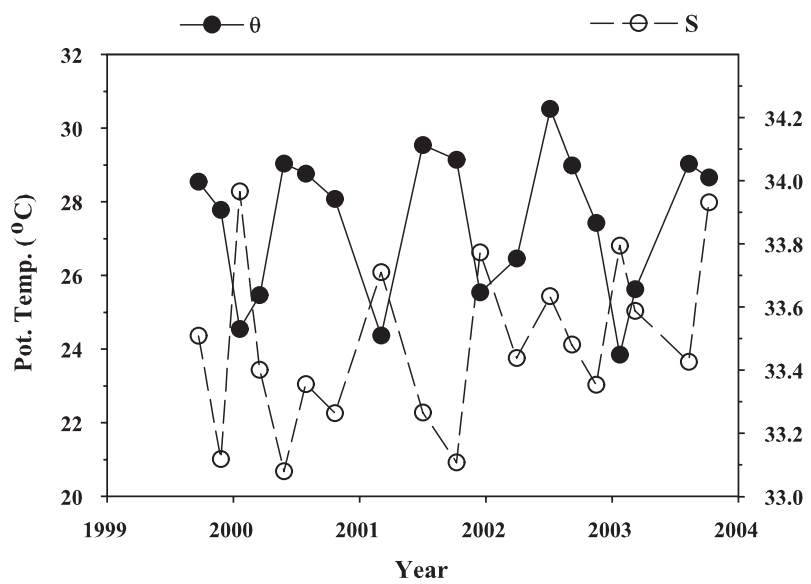

(B)

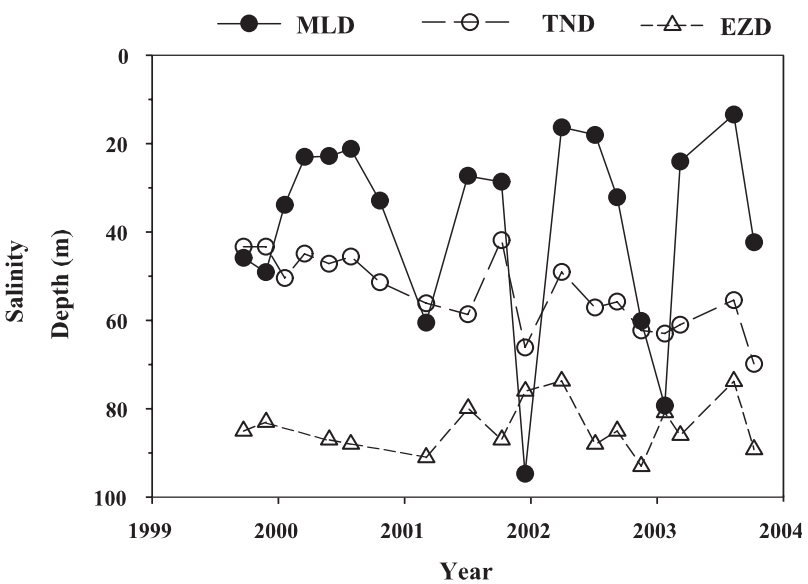

Fig. 6. Temporal variations in (A) the average potential temperature, $\theta$, and the average salinity, $\mathrm{S}$ in the mixed layer, and, (B) the mixedlayer depth (MLD), euphotic zone depth (EZD) and top of the nutricline depth (TND) at the SEATS station between September 1999 and October 2003.

(A) $(\mathbf{N}+\mathbf{N})(\mu \mathbf{M})$

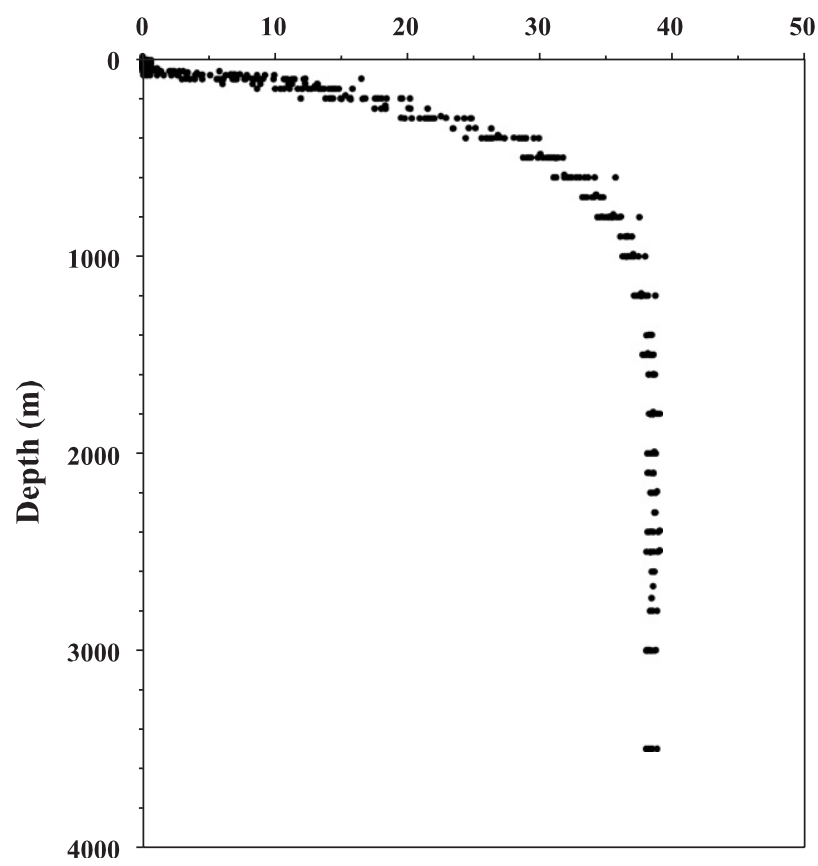

(B)

50

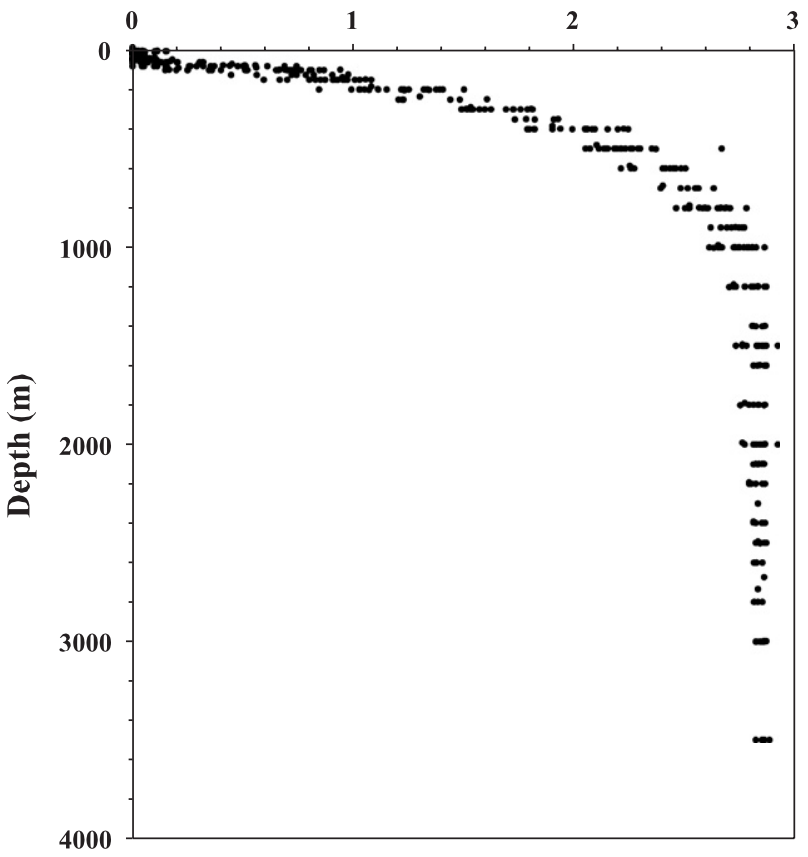

Fig. 7. The vertical distributions of $(A)(N+N)$ and (B) SRP at the SEATS station between September 1999 and October 2003.

availability of light could have an influence. Chen (2005) also suggested that the availability of nutrients is a more critical limiting factor on primary production in the northern SCS than the availability of light. Relative to the MLD, the TND was deeper between the spring and the fall but it was similar to or even shallower than the MLD in the winter. Thus, although the nutrients in the upper nutricline could not be made available for supporting photosynthetic activities by vertical mixing for 
(A)

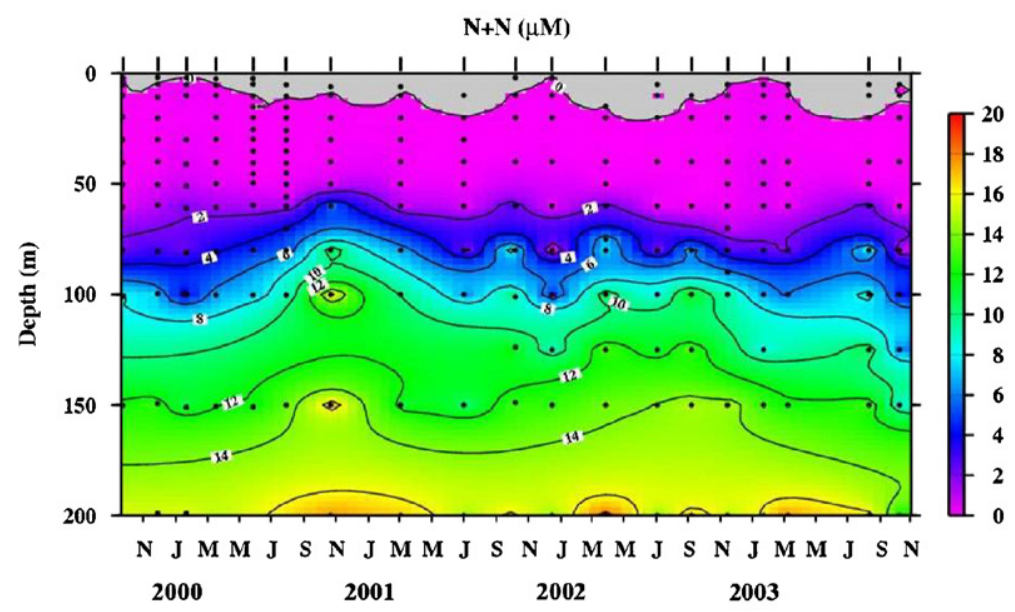

(B)

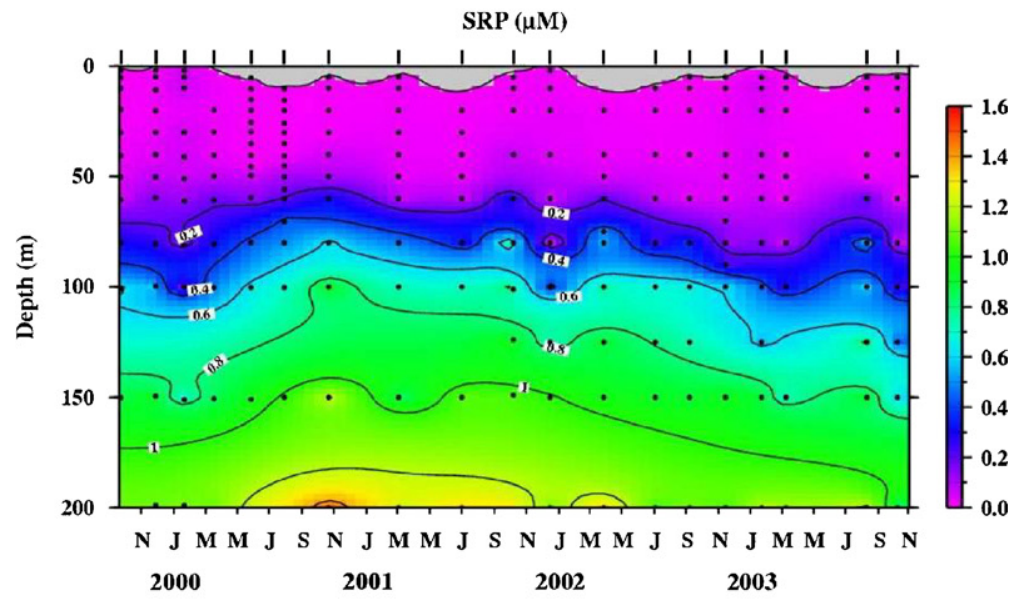

(C)

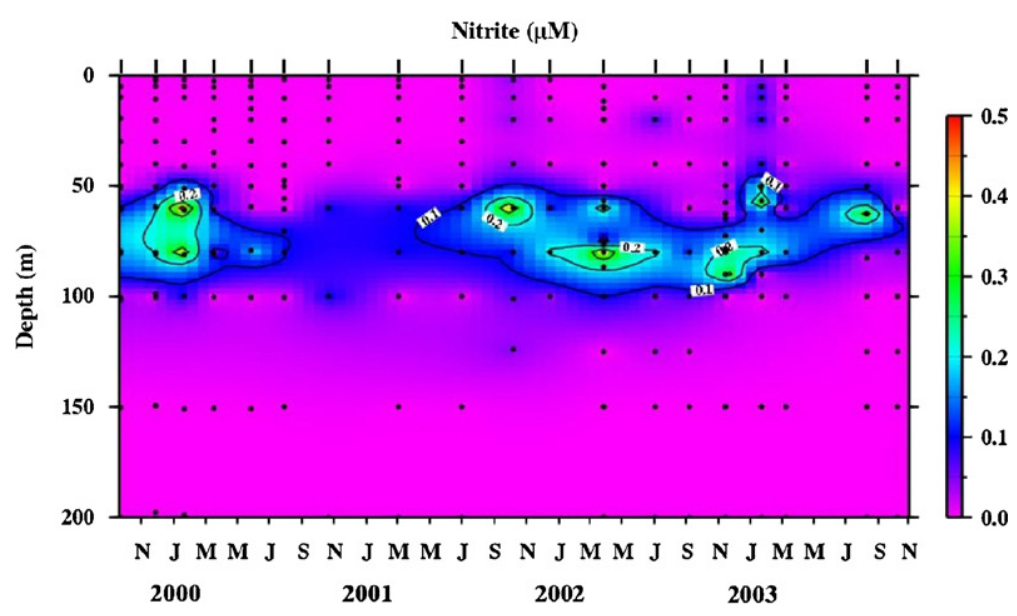

Fig. 8. Temporal variations in (A) N+N, (B) SRP and (C) nitrite in the top $200 \mathrm{~m}$ at the SEATS station between September 1999 and October 2003. The times of sampling are indicated by the hash marks along the top boundary of the figure. The dots in the figure indicate the sampling depths. 


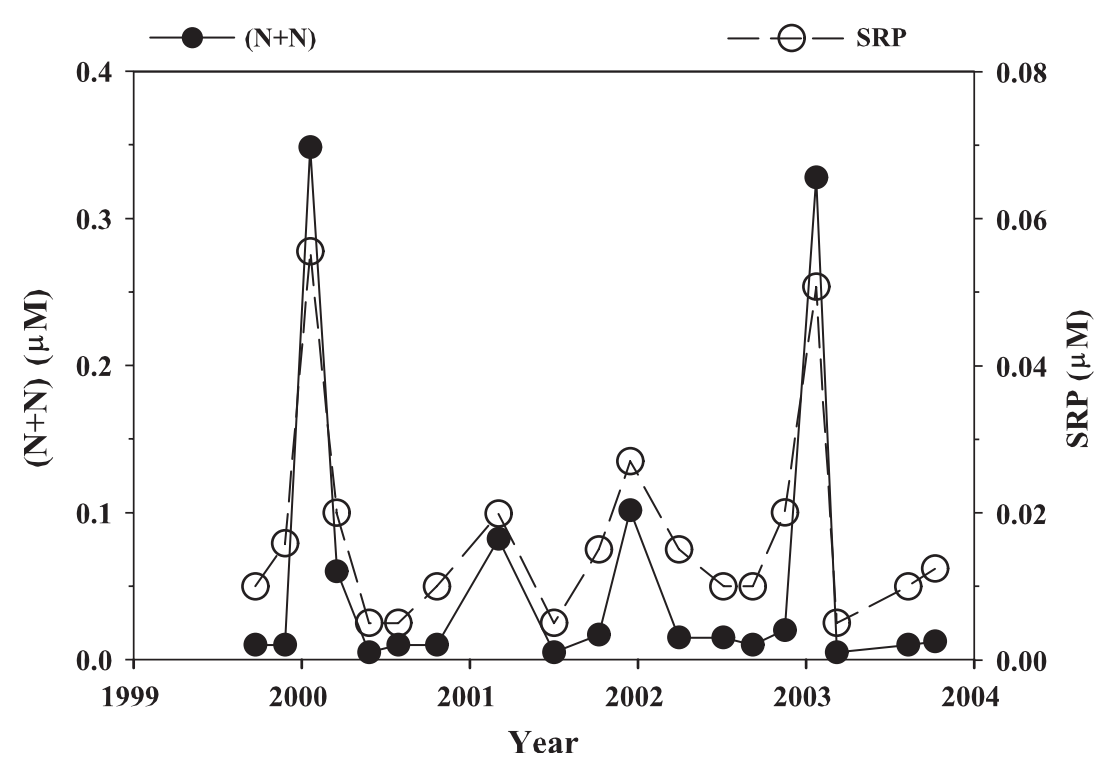

Fig. 9. Temporal variations in the average concentrations of $(\mathrm{N}+\mathrm{N})$ and $\mathrm{SRP}$ in the mixed layer at the SEATS station between September 1999 and October 2003.

most of the year, they could become available in the winter under enhanced vertical mixing.

\subsection{Nutrient- $\theta$ and nutrient-S relationships}

The relationship between $(\mathrm{N}+\mathrm{N})$ and potential temperature is shown in Fig. 10A. The relationship between SRP and potential temperature followed a similar pattern qualitatively. In both cases, as a first approximation, they were linearly related to potential temperature below about $22^{\circ} \mathrm{C}$. Ordinary linear regression analyses yielded the following relationships:

$$
\begin{array}{r}
(\mathrm{N}+\mathrm{N})(\mu \mathrm{M})=-1.80( \pm 0.01) \theta+43.5( \pm 0.1) \\
r^{2}=0.981, \quad N=351,
\end{array}
$$

$$
\begin{array}{r}
\operatorname{SRP}(\mu \mathrm{M})=-0.133( \pm 0.001) \theta+3.21( \pm 0.01) \\
r^{2}=0.979, N=350,
\end{array}
$$

where $r$ is the correlation coefficient and $N$ is the number of data points used in the analysis. According to these relationships, mathematically, the concentrations of $(\mathrm{N}+\mathrm{N})$ and SRP should drop to undetectable levels at temperatures of 24.2 and $24.1{ }^{\circ} \mathrm{C}$, respectively. These relationships did not vary significantly from cruise to cruise. In the 18 individual cruises where the deep waters were sampled, the correlation coefficients, $r^{2}$, were mostly above 0.98 and they never dropped below 0.92 . The slopes and intercepts in the relationship between $(\mathrm{N}+\mathrm{N})$ and potential temperature in individual cruises stayed within the narrow ranges of -1.63 to -2.07 , with an average of $-1.8 \pm 0.1 \mu \mathrm{M}^{\circ} \mathrm{C}^{-1}$, and, $41.9-44.8$ with an average of $43.4 \pm 0.7 \mu \mathrm{M}$, respectively. In the corresponding relationships between SRP and potential temperature, the slopes and intercepts ranged between -0.119 and -0.148 , with an average of $-0.133 \pm 0.001 \mu \mathrm{M}^{\circ} \mathrm{C}^{-1}$, and, between 3.10 and 3.33 with an average of $3.21 \pm 0.01 \mu \mathrm{M}$. Thus, below around $22^{\circ} \mathrm{C}$, the nutrients were quasi-conservative and temperature could be a useful tracer for the nutrients. Above this temperature, the concentrations of $(\mathrm{N}+\mathrm{N})$ and SRP stayed almost invariant at around their respective detection limits.

Superimposed on these general linear trends were secondary features. Two slight inflexion points were found at 15 and $8{ }^{\circ} \mathrm{C}$ in the relationships between $(\mathrm{N}+\mathrm{N})$ or SRP and potential temperature. Gong et al. (1992) also reported similar inflexion points at 15 and $5{ }^{\circ} \mathrm{C}$. The corresponding inflexion points in the nutrient-salinity relationships, at $S=34.6$ and 34.4, were even more conspicuous (Fig. 10B). The inflexion point at $\theta=8{ }^{\circ} \mathrm{C}$ and $S=34.4$ corresponded approximately with the core of the NPIW. The scatters in the relationships, which are indicative of temporal variations in potential temperature, salinity and the concentrations of the nutrients, increased towards the upper end of the temperature ranges of these relationships and became quite noticeable at temperatures above $15^{\circ} \mathrm{C}$. Thus, the Tropical Water, with a potential 
(A)

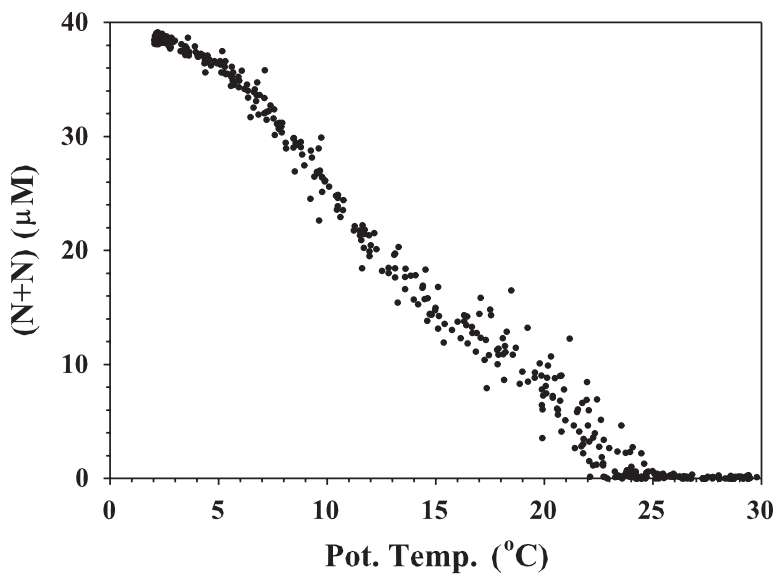

(B)

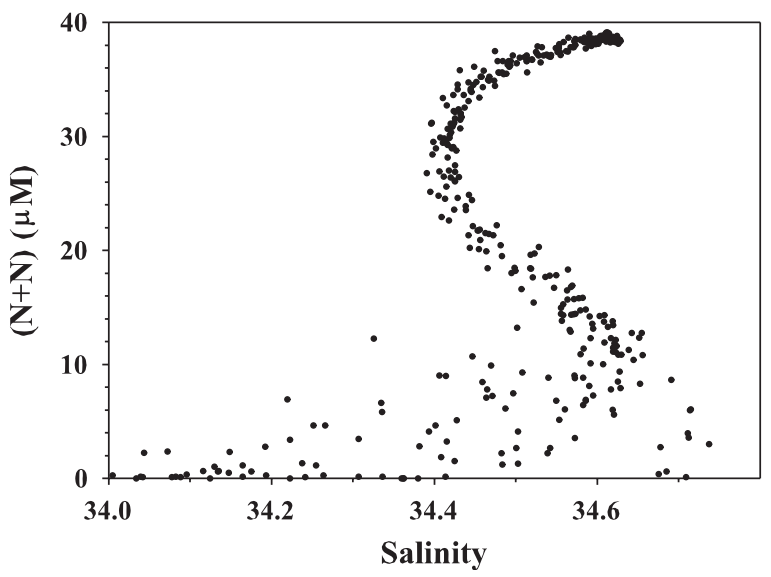

Fig. 10. The relationship between $(\mathrm{N}+\mathrm{N})$ and (A) potential temperature and (B) salinity at the SEATS station between September 1999 and October 2003.

temperature of $18^{\circ} \mathrm{C}$, was located at a depth where its composition was subject to temporal variations to some degree.

\subsection{Nutrient dynamics as indicated by the} relationship between $(N+N)$ and $S R P$ and the distributions of $(N+N) / P$ and $N^{*}$

The relationship between $(\mathrm{N}+\mathrm{N})$ and SRP during all the cruises is shown in Fig. 11. A model II linear regression analysis indicates that it may be represented by the relationship:

$$
\begin{gathered}
{[\mathrm{N}+\mathrm{N}](\mu \mathrm{M})=13.63( \pm 0.03)[\mathrm{SRP}](\mu \mathrm{M})} \\
-0.18( \pm 0.06) \quad r^{2}=0.997, N=547 .
\end{gathered}
$$

In the 18 individual cruises, the correlation coefficients, $r^{2}$, exceeded 0.99 in all cases. The slopes

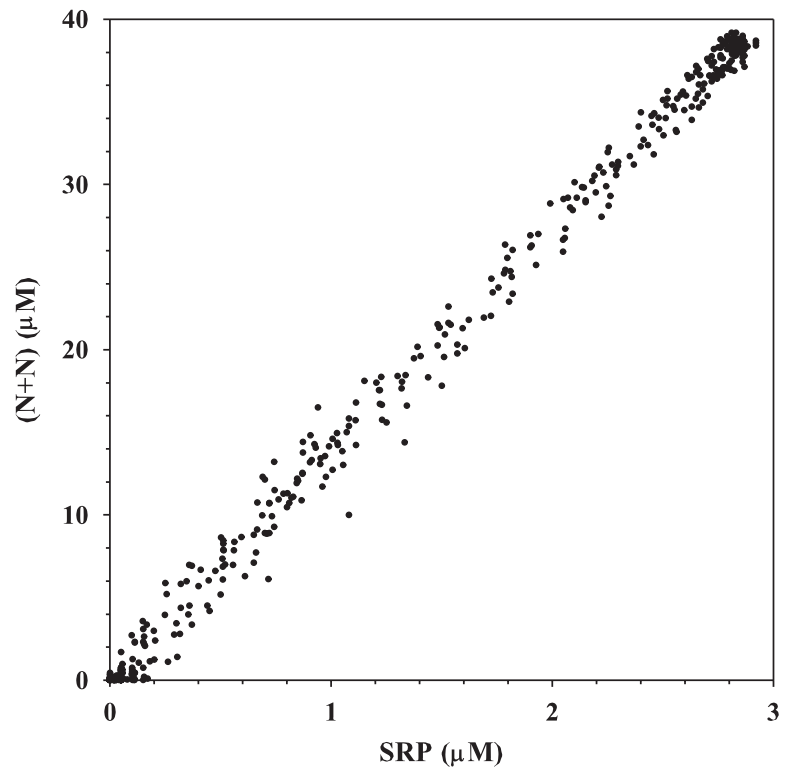

Fig. 11. The relationship between $(\mathrm{N}+\mathrm{N})$ and $\mathrm{SRP}$ at the SEATS station between September 1999 and October 2003.

varied between 13.2 and 14.1, with an average of $13.6 \pm 0.3 \mu \mathrm{M} \mathrm{MM}^{-1}$, while the intercepts varied between -1.3 and +1.1 with an average of $-0.2 \pm 0.6 \mu \mathrm{M}$. Thus, the relationships stayed relatively constant from cruise to cruise. In the Redfield biological pump, remineralization leads to the release of $(\mathrm{N}+\mathrm{N})$ and SRP to the water column in a molar ratio of 16:1 (Redfield et al., 1963). Thus, the observed slopes were consistently and significantly lower than the Redfield ratio. If the Redfield ratio is a robust value (Anderson and Sarmiento, 1994), these lower values may be accounted for by the removal of $(\mathrm{N}+\mathrm{N})$ without a corresponding removal of SRP by denitrification in the water column and in the sediments in the oceans (Deutsch et al., 2001). The small negative average intercept was indistinguishable from zero. Thus, while, based on ship-board enrichment experiments, Chen (2005) reported that nitrate is more limiting than SRP in the northern SCS, the data here only yielded a minimal indication of nitrogen limitation.

The dynamics in the remineralization of organic matter in the upper water and especially in the nutricline may be further explored by examining the variations in the $(\mathrm{N}+\mathrm{N}) / \mathrm{SRP}$ ratio and the $\mathrm{N}$-anomaly, $\mathrm{N}^{*}$ (Gruber and Sarmiento, 1997; Deutsch et al., 2001). Again, in the Redfield model, the oxidation of the hypothetical organic matter should yield $(\mathrm{N}+\mathrm{N})$ and $\mathrm{SRP}$ in a molar ratio of $16: 1$. However, organic matter with higher N:P ratio 
can be formed by nitrogen fixation when molecular nitrogen rather than combined nitrogen is used as the source of nitrogen in primary production by specific marine phytoplankton. Although the exact value of the N:P ratio in nitrogen fixing organisms is not yet known definitively, a value as high as 125:1 has been proposed (Karl et al., 1992; Gruber and Sarmiento, 1997). The remineralization of this nitrogen-rich organic matter will elevate the $(\mathrm{N}+\mathrm{N})$ /SRP ratio in the water. On the other hand, if denitrification occurs, combined nitrogen is converted into molecular nitrogen and this process will reduce the $(\mathrm{N}+\mathrm{N}) / \mathrm{SRP}$ ratio in the water. These modifications on the $(\mathrm{N}+\mathrm{N}) / \mathrm{SRP}$ ratio may be presented as a $\mathrm{N}$-anomaly, $\mathrm{N}^{*}$, which is defined by Deutsch et al. (2001) as

$\mathrm{N}^{*}=\mathrm{N}-16 \mathrm{P}+2.90$,

where $\mathrm{N}$ and $\mathrm{P}$ are the concentrations of nitrate and SRP in $\mu \mathrm{mol} \mathrm{kg}{ }^{-1}$. This definition was modified slightly here so that $\mathrm{N}$ and $\mathrm{P}$ are the concentrations of $(\mathrm{N}+\mathrm{N})$ and SRP in $\mu \mathrm{M}$. These modifications do not change the meaning or the numerical value of $\mathrm{N}^{*}$ to any significant extent. Aside from the effects of mixing, $\mathrm{N}^{*}$ represents the deviation from the Redfield biological pump as a result of the sum of the effects of denitrification and nitrogen fixation. The constant of $2.90 \mu \mathrm{M}$ is the global average deficit in nitrate that resulted from denitrification. Thus, the global average $\mathrm{N}^{*}$ is assumed to be 0 . Since this assumption has not been proven, $\mathrm{N}^{*}$ is meaningful primarily as a relative, rather than an absolute, value, with a more positive value indicating a more dominant effect of nitrogen fixation over denitrification. Concentrations of $\mathrm{N}^{*}$ were computed in samples where the concentrations of $(\mathrm{N}+\mathrm{N})$ and SRP exceeded 1 and $0.1 \mu \mathrm{M}$, respectively. At lower concentrations, the estimated values of $\mathrm{N}^{*}$ were too uncertain to be meaningful. Based on the analytical uncertainties in the determinations of $(\mathrm{N}+\mathrm{N})$ and $\mathrm{SRP}$, the uncertainties in $(\mathrm{N}+\mathrm{N}) / \mathrm{SRP}$ and $\mathrm{N}^{*}$ were $\pm 2 \%$ and $\pm 0.5 \mu \mathrm{M}$.

The data quality in $(\mathrm{N}+\mathrm{N}) / \mathrm{SRP}$ and $\mathrm{N}^{*}$ also was assessed by examining their consistency in the deep water. Their ranges and average values at 1500-1600 $\mathrm{m}, 2400-2700 \mathrm{~m}$ and $2800-3000 \mathrm{~m}$ during the sampling period are listed in Table 1 . The data from 2400 to $2700 \mathrm{~m}$ are shown in Fig. 12. Both $(\mathrm{N}+\mathrm{N}) / \mathrm{SRP}$ and $\mathrm{N}^{*}$ were remarkably constant in these deep waters, where temporal variations were not expected. The variations could be accounted for readily by the analytical uncertainties in the determination of $(\mathrm{N}+\mathrm{N})$ and $\mathrm{SRP}$ alone. Thus, any changes in $(\mathrm{N}+\mathrm{N}) / \mathrm{SRP}$ or $\mathrm{N}^{*}$ that were significantly larger than the analytical uncertainties should then reflect real changes in nutrient dynamics. The average $(\mathrm{N}+\mathrm{N}) / \mathrm{SRP}$ in waters below $1000 \mathrm{~m}$ was $13.5 \mu \mathrm{M} \mu \mathrm{M}^{-1}$, and this value was similar to that found at the HOT station (Karl et al., 2001).

The vertical distributions of $(\mathrm{N}+\mathrm{N}) / \mathrm{SRP}$ and $\mathrm{N}^{*}$ are shown in Fig. 13. Both the average values and the variability decreased with depth. Thus, the molar ratio of $(\mathrm{N}+\mathrm{N}) / \mathrm{SRP}$ decreased from $14.3 \pm 2.2$ in the Tropical Water to $13.8 \pm 0.5$ in the NPIW and to $13.6 \pm 0.2$ in the deep waters below $1500 \mathrm{~m}$. Correspondingly, $\mathrm{N}^{*}$ decreased from $1.3 \pm 2.0$ to $-1.8 \pm 0.2$ and to $-4.0 \pm 0.6 \mu \mathrm{M}$ (Table 1). The variability in the upper water was significantly larger than the analytical uncertainties and it was especially large in the upper nutricline between 50 and $150 \mathrm{~m}$, where the primary nitrite maximum was located and nitrification was the most intensive. At these depths, $(\mathrm{N}+\mathrm{N}) / \mathrm{SRP}$ ranged between 4 and 24 while $N^{*}$ ranged between -4 and $6 \mu \mathrm{M}$. Values of $(\mathrm{N}+\mathrm{N}) / \mathrm{SRP}$ below the Redfield ratio of 16 could be explained by the preferential release of SRP over $(\mathrm{N}+\mathrm{N})$ during nitrification (Karl et al., 2001) or by the selective removal of $(\mathrm{N}+\mathrm{N})$ independent of SRP in sedimentary denitrification. Indeed, in a survey of the distributions of dissolved organic nitrogen and phosphorus, or DON and DOP, and, particulate organic nitrogen and phosphorus, or PON and POP, in the northern SCS, Hung et al. (2007) reported that the DON:DOP atomic ratio was higher in the nutricline than in the euphotic zone, while the PON:POP atomic ratio far exceeded the Redfield stoichiometry, and they attributed these phenomena to the preferential regeneration of SRP over $(\mathrm{N}+\mathrm{N})$. On the other hand, ratios of $(\mathrm{N}+\mathrm{N})$ / SRP above 16 require the nitrification of nitrogenrich organic matter with the N:P ratio exceeding 16 . Gruber and Sarmiento (1997) surveyed the distributions of $\mathrm{N}^{*}$ in all the major oceans of the world. Deutsch et al. (2001) further analyzed data from the Pacific Ocean. They reported that values of $\mathrm{N}^{*}$ exceeding $2 \mu \mathrm{M}$ would be considered high, and would suggest significant effects from nitrogen fixation. Thus, the high values at the upper end of the ranges of $(\mathrm{N}+\mathrm{N}) / \mathrm{SRP}$ and $\mathrm{N}^{*},(\mathrm{~N}+\mathrm{N}) /$ SRP $>16$ and $\mathrm{N}^{*}>2 \mu \mathrm{M}$, in the upper nutricline at the SEATS station might be indicative of the nitrification of organic matter formed by nitrogen 


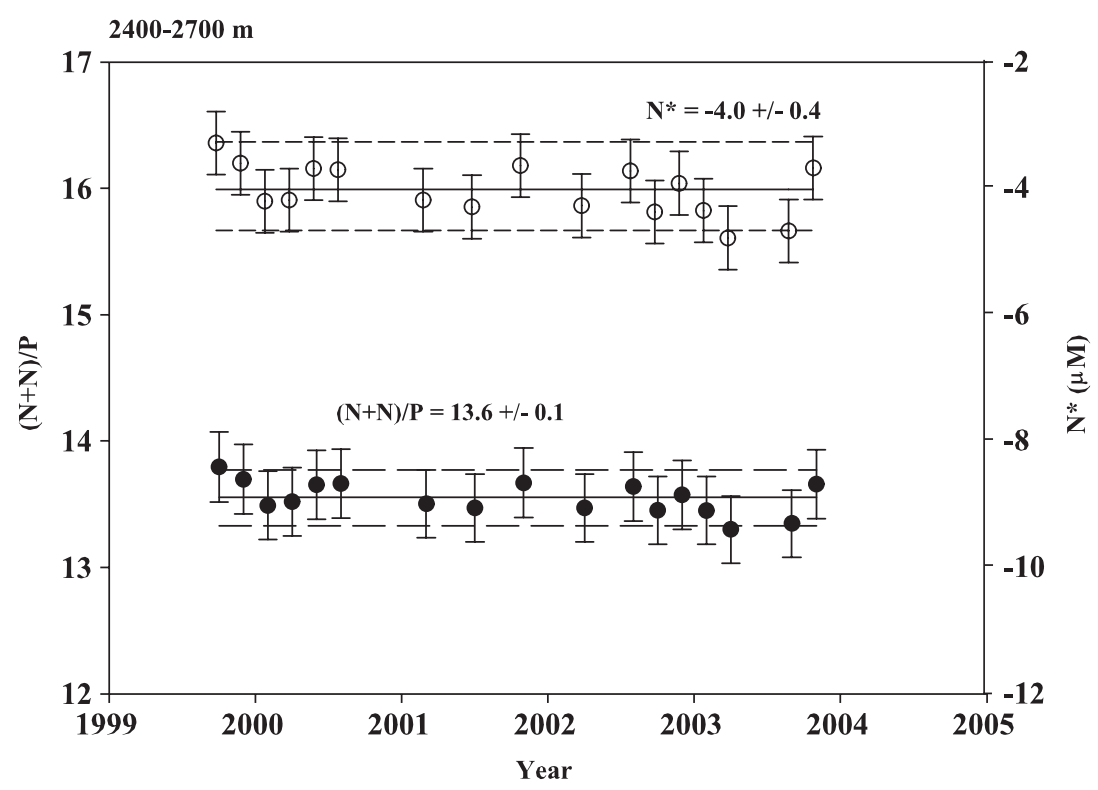

Fig. 12. Temporal variations in the $(\mathrm{N}+\mathrm{N}) / \mathrm{SRP}$ and $\mathrm{N}^{*}$ at $2400-2700 \mathrm{~m}$ in the deep waters at the SEATS station between September 1999 and October 2003.

fixation. By using methods for determining low concentrations of $(\mathrm{N}+\mathrm{N})$ and SRP, Hung et al. (2007) surveyed the distributions of $(\mathrm{N}+\mathrm{N})$ and SRP in the mixed layer in the northern SCS and they found ratios of $(\mathrm{N}+\mathrm{N}) / \mathrm{SRP}$ that were far below the Redfield stoichiometry. They suggested that the northern SCS is nitrogen limited so that nitrogen fixation may be favored. At the HOT station, while the molar ratio of $(\mathrm{N}+\mathrm{N}) / \mathrm{SRP}$ was invariably significantly below 16 in the nutricline, ratios exceeding 16 were commonly found once the dissolved organic nutrients were taken into account (Karl et al., 2001). In the North Atlantic, molar ratios of $(\mathrm{N}+\mathrm{N}) / \mathrm{SRP}$ exceeding 16 were found in the shallower waters (Fanning, 1992). Karl et al. (2001) suggested that the elevated ratios in both cases were an indication of the significant contribution of nitrogen fixation to the nutrient dynamics.

The core of the Tropical Water at the salinity maximum was situated at about $150 \mathrm{~m}$ in the upper nutricline, where seasonal effects could still be detected. The variations of $(\mathrm{N}+\mathrm{N}) / \mathrm{SRP}$ and $\mathrm{N}^{*}$ in this water in the different months of the year are shown in Fig. 14. They ranged between 9 and $18 \mu \mathrm{M} \mu \mathrm{M}^{-1}$ and -5 to $4 \mu \mathrm{M}$, respectively. These ranges of values far exceeded what could be explained by analytical uncertainties alone. While there were significant inter-annual variations, the high values, $(\mathrm{N}+\mathrm{N}) / \mathrm{SRP}>16$ and $\mathrm{N}^{*}>2 \mu \mathrm{M}$, were found exclusively between September and
April between fall and early spring. The average values of $(\mathrm{N}+\mathrm{N}) / \mathrm{SRP}$ and $\mathrm{N}^{*}$ during this period of time in the year were $15.0 \pm 1.9$ and $1.9 \pm 1.6 \mu \mathrm{M}$, respectively. In contrast, the average values were $12.6 \pm 2.2$ and $-0.3 \pm 2.5 \mu \mathrm{M}$ between May and August in the late spring and summer. If the nutrients regenerated from the nitrogen-rich organic particles formed in episodes of nitrogen fixation were used for supporting primary production by phytoplankton in general according to the Redfield stoichiometry, then phosphate-limitation might have followed and it might be manifested as a positive intercept in the relationship between $(\mathrm{N}+\mathrm{N})$ and SRP. Indeed, while the average value of the intercepts in the relationships between $(\mathrm{N}+\mathrm{N})$ and SRP over the sampling period was indistinguishable from zero and, in the data from individual cruises most of the intercepts were either negative or indistinguishable from zero, there were two high positive values of $1.1 \pm 0.3$ and $0.8 \pm 0.4 \mu \mathrm{M}$ that were significantly larger than the statistical uncertainties and both were found between September and April. In the northern SCS, the concentrations of aerosols and the frequency of the deposition of dusts are higher between September and April than in the rest of the year (Merrill et al., 1989; Husar et al., 1997). Lin et al. (2007) also report that the aerosol optical thickness, which is indicative of the concentration of aerosols, at the SEATS station was higher during these 
(A)

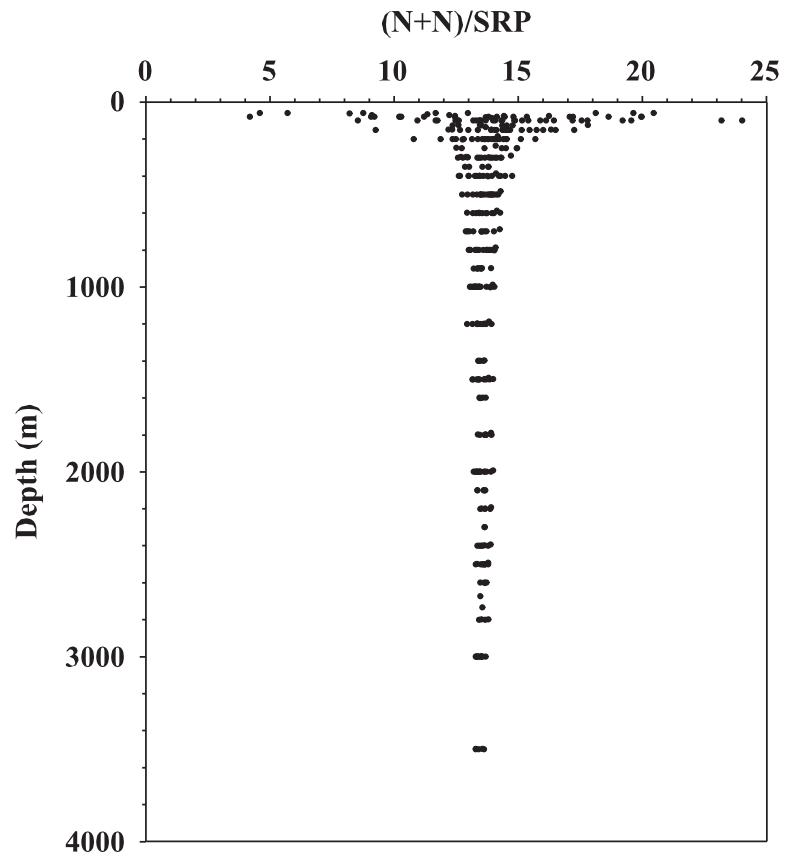

(B)

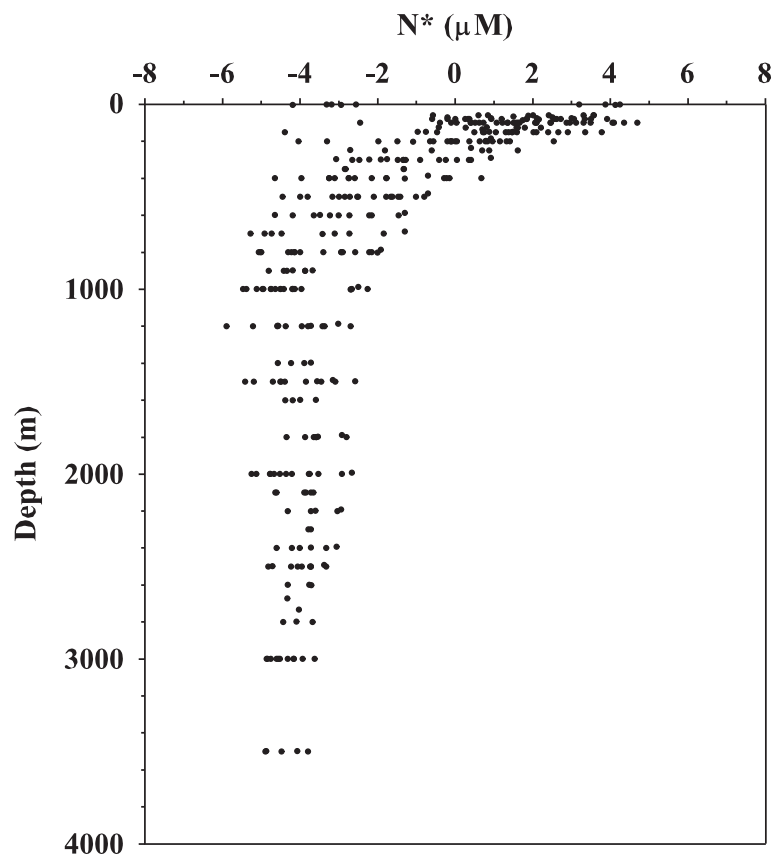

Fig. 13. The vertical distributions of $(A)(N+N) / S R P$ and $(B) N^{*}$ at the SEATS station between September 1999 and October 2003.

months, and that the major sources of these aerosols were the dusts from Central Asian and the particles emitted by the industrial activities in China. Liu et al. (2007) found that the $\delta^{15} \mathrm{~N}$ in the particulate organic matter in the mixed layer at the SEATS station was particularly low during these same months and suggested a more significant contribution of organic matter from nitrogen fixation during this time period. The coherence of all these seasonal patterns is consistent with the enhancement of nitrogen fixation in oligotrophic water by atmospherically derived iron from the deposition of aerosols (Wong et al., 2002).

\subsection{Box modeling of $(N+N)$ and $S R P$ in the mixed layer at SEATS}

\subsection{1. $N$ limitation under Redfield stoichiometry}

While there were conspicuous intra-annual variations in the concentrations of $(\mathrm{N}+\mathrm{N})$ and SRP in the mixed layer, they followed well-defined seasonal cycles so that there were annual average conditions. Then, if the dynamics of $(\mathrm{N}+\mathrm{N})$ and SRP in the mixed layer at the SEATS station operate according to the Redfield model, and, if these nutrients are supplied to the mixed layer primarily from vertical mixing between the mixed layer and the upper nutricline, and are removed from the mixed layer by the formation and settling of organic particles, a box model constrained by primary production may be set up for their cycling in the mixed layer. In this model, water from the upper nutricline with $(\mathrm{N}+\mathrm{N}) / \mathrm{SRP}<16$ is added by upwelling to the mixed layer where $(\mathrm{N}+\mathrm{N})$ and $\mathrm{SRP}$ are used in photosynthetic activities in the Redfield ratio of 16:1. Organic particles with this N:P ratio are then exported to the deep water by particle settling. Under this scenario, $(\mathrm{N}+\mathrm{N})$ is the limiting nutrient that is used in the mixed layer in excess of its supply from the deeper water. This would result in a build up of SRP in the mixed layer over time. Since $(\mathrm{N}+\mathrm{N})$ is the limiting nutrient, its concentration would approach zero. If the mixed layer is at a steady state with respect to $(\mathrm{N}+\mathrm{N})$, the material balance for $(\mathrm{N}+\mathrm{N})$ would be:

$$
\begin{aligned}
& \partial\left(N_{\mathrm{s}} V_{\mathrm{s}}\right) / \partial t=0=E N_{\mathrm{d}}-E N_{\mathrm{s}}-\operatorname{PP} r_{\mathrm{n}}, \\
& \therefore \quad E=\left(\operatorname{PP} r_{\mathrm{n}}\right) /\left(N_{\mathrm{d}}-N_{\mathrm{s}}\right),
\end{aligned}
$$

where $N_{\mathrm{s}}$ and $N_{\mathrm{d}}$ are the concentrations of $(\mathrm{N}+\mathrm{N})$ in the mixed layer and the upper nutricline, $V_{\mathrm{s}}$ is the volume of the mixed layer, $t$ is time, $E$ is the water exchange rate between the mixed layer and the upper nutricline, $\mathrm{PP}$ is net primary production, and $r_{\mathrm{n}}$ is the nitrogen to carbon ratio in organic matter formed in primary production. $\mathrm{PP} r_{\mathrm{n}}$ is the settling flux of particulate nitrogen in organic particles from 
(A)

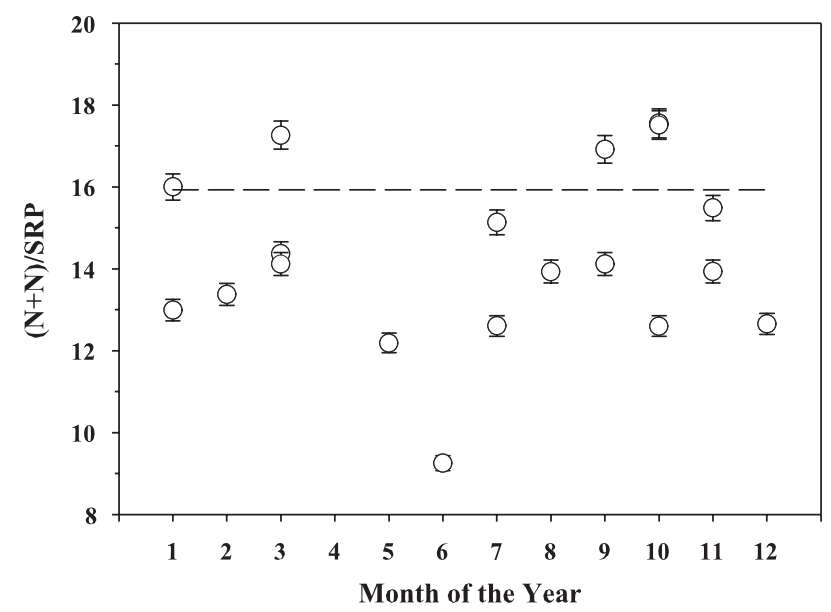

(B)

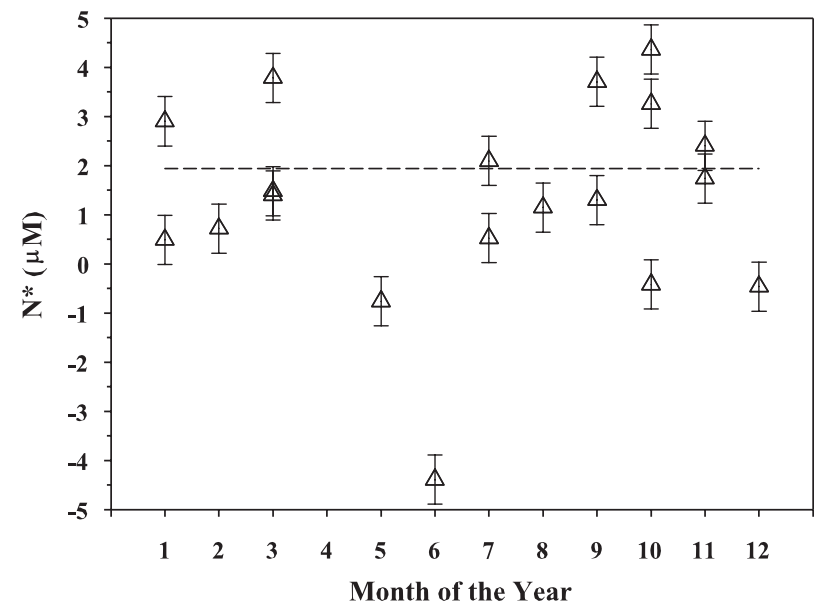

Fig. 14. Temporal variations in $(A)$ the $(N+N) / S R P$ and $(B) N^{*}$ in the Tropical Water at the salinity maximum at about $150 \mathrm{~m}$ in the upper waters at the SEATS station between September 1999 and October 2003.

the mixed layer to the upper nutricline. PP in the northern SCS is not well known. A small number of direct observations yielded a value of $120 \mathrm{~g}$ $\mathrm{C} \mathrm{m}^{-2} \mathrm{yr}^{-1}$ (Chen, 2005). A bio-physical modeling exercise suggested a rate of $130 \mathrm{~g}-\mathrm{Cm}^{-2} \mathrm{yr}^{-1}$ (Liu et al., 2002). Thus, by assuming a mean of $125 \mathrm{~g}-\mathrm{C} \mathrm{m}^{-2} \mathrm{yr}^{-1}$ and an uncertainty of $\pm 20 \%$ or $\pm 25 \mathrm{~g}-\mathrm{C} \mathrm{m}^{-2} \mathrm{yr}^{-1}$, a range of $100-150 \mathrm{~g}-\mathrm{C} \mathrm{m}^{-2} \mathrm{yr}^{-1}$ was used in the present modeling exercise. From Eq. $\left(1^{\prime}\right)$, E can be estimated to be $41 \mathrm{~m} \mathrm{yr}^{-1}$ at PP of $125 \mathrm{~g}-\mathrm{C} \mathrm{m}^{-2} \mathrm{yr}^{-1}$ at the Redfield $r_{\mathrm{n}}$ of $16 / 106$ since $N_{\mathrm{d}}$ and $N_{\mathrm{s}}$ are 38.4 and about $0 \mu \mathrm{M}$, respectively. This value is in reasonable agreement with $55 \mathrm{~m} \mathrm{yr}^{-1}$, estimated from the mass balance of salt and water (Chen et al., 2002).

If the concentration of SRP in the mixed layer, $P_{\mathrm{s}}$, is time-dependent, then, the corresponding material balance for SRP in the mixed layer is

$$
\begin{aligned}
\partial\left(P_{\mathrm{s}} V_{\mathrm{s}}\right) / \partial t & =E P_{\mathrm{d}}-E P_{\mathrm{s}}-\mathrm{PP} r_{\mathrm{p}} \\
& =E\left(P_{\mathrm{d}}-P_{\mathrm{s}}\right)-\operatorname{PP} r_{\mathrm{p}},
\end{aligned}
$$

where $P_{\mathrm{s}}$ and $P_{\mathrm{d}}$ are the concentrations of SRP in the mixed layer and the upper nutricline, $r_{\mathrm{p}}$ is the phosphorus to carbon ratio in organic matter formed in primary production and $\mathrm{PP} r_{\mathrm{p}}$ is the settling flux of phosphorus in organic particles. By substituting Eq. (1') into Eq. (2)

$\partial\left(P_{\mathrm{s}} V_{\mathrm{s}}\right) / \partial t=\left(\operatorname{PP} r_{\mathrm{n}}\right)\left(P_{\mathrm{d}}-P_{\mathrm{s}}\right) /\left(N_{\mathrm{d}}-N_{\mathrm{s}}\right)-\operatorname{PP} r_{\mathrm{p}}$,

$\partial P_{\mathrm{s}} / \partial t=\left(\mathrm{PP} / V_{\mathrm{s}}\right) r_{\mathrm{p}}\left[r\left(P_{\mathrm{d}}-P_{\mathrm{s}}\right) /\left(N_{\mathrm{d}}-N_{\mathrm{s}}\right)-1\right]$, where $r$ is the nitrogen to phosphorus ratio in organic matter formed by primary production or $r=r_{\mathrm{n}} / r_{\mathrm{p}}$. The solution to Eq. (4) is

$$
\begin{aligned}
P_{\mathrm{s}}= & {\left[P_{\mathrm{d}}-\left(N_{\mathrm{d}} / r\right)\right]+\left\{P_{\mathrm{so}}-\left[P_{\mathrm{d}}-\left(N_{\mathrm{d}} / r\right)\right]\right\} } \\
& \exp \left[-\left(\mathrm{PP} / V_{\mathrm{s}}\right)\left(r_{\mathrm{n}} / N_{\mathrm{d}}\right) t\right],
\end{aligned}
$$

where $P_{\text {so }}$ is the concentration of SRP in the mixed layer at $t=0$. Since potential temperature and salinity, and, $(\mathrm{N}+\mathrm{N})$ and potential temperature were approximately linearly related to each other between the mixed layer and the salinity maximum in individual cruises (Figs. 4 and 10), as a first approximation, the Tropical Water at the salinity maximum is taken as the water in the upper nutricline that mixes with the water in the mixed layer. Thus, $P_{\mathrm{d}}$ and $N_{\mathrm{d}}$ equal $0.82 \pm 0.19$ and $11.6 \pm 2.8 \mu \mathrm{M}$, respectively (Table 1 ). If the initial condition in the mixed layer is assumed to be similar to the annual average condition, then $P_{\text {so }}$ is given by the average concentration of SRP in the surface mixed layer and that can be estimated from Fig. 9 to be about $0.02 \mu \mathrm{M}$. This estimated value is consistent with the limited number of measurements of low-level SRP in the surface northern SCS (Wu et al., 2003; Chen, 2005). In the Redfield model, $r_{\mathrm{n}}=16 / 106 \mathrm{~mol}-\mathrm{N}$ mol-C $\mathrm{C}^{-1}$ and $r=16 \mathrm{~mol}-\mathrm{N}$ mol- $\mathrm{P}^{-1}$. The average MLD was $38 \mathrm{~m}$. Thus, $V_{\mathrm{s}}=38 \times 10^{3} 1 \mathrm{~m}^{-2}$. PP is again assumed to be $125 \mathrm{~g}-\mathrm{C} \mathrm{m}^{-2} \mathrm{yr}^{-1} \pm 20 \%$. The resulting relationships between $P_{\mathrm{s}}$ and time under the average conditions, at maximum concentrations of nutrients and maximum and minimum PP, and at minimum 
concentrations of nutrients and maximum and minimum PP are shown in Fig. 15. In all cases, the concentration of SRP in the mixed layer increases systematically and rapidly with time and reaches a steady-state concentration, which ranges between 0.08 and $0.11 \mu \mathrm{M}$, in a year or less. These steady-state concentrations predicted by the model should be easily detectable and are significantly higher than the observed concentrations, which never exceeded $0.06 \mu \mathrm{M}$ even when the seasonal variations had also been taken into considerations (Fig. 9). The structure of Eq. (5) indicates that the steady-state concentration is given by $\left[P_{\mathrm{d}}-\left(N_{\mathrm{d}} / r\right)\right]$ so that it is independent of PP, $V_{\mathrm{s}}, r_{\mathrm{n}}$ and $P_{\text {so. }}$. The primary role of these other parameters is in determining the amount of time that is needed to reach the steady-state concentration since they only appear in the exponential term. Thus, regardless of the uncertainties in PP, $V_{\mathrm{s}}, r_{\mathrm{n}}$ and $P_{\text {so }}$, the model will still predict a sizable buildup in SRP in the mixed layer that is not supported by the observed concentrations. Furthermore, since the steady state concentrations can be reached in a year or less, even if a steady state had not been reached at the beginning of this study, those elevated concentrations should have been found by the end of the study period, which covered 4 years. The discrepancy between the model predicted and the observed concentrations of SRP in the mixed layer at the SEATS station indicates that the nutrient dynamics at the SEATS station do

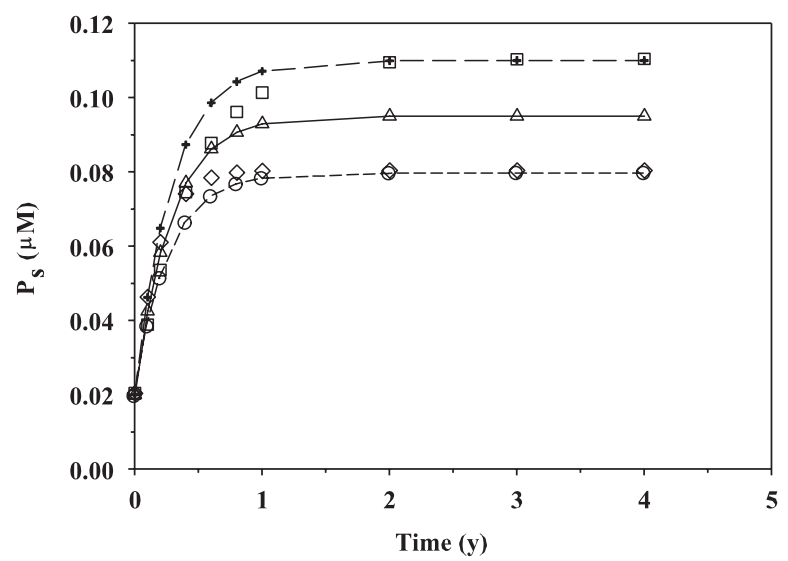

Fig. 15. Model predicted relationships between the concentration of SRP in the mixed layer, $P_{\mathrm{s}}$, and time. $\Delta$-average concentrations of SRP and $(\mathrm{N}+\mathrm{N})$, average $\mathrm{PP} ;+-$ maximum concentrations of SRP and $(\mathrm{N}+\mathrm{N})$, maximum $\mathrm{PP} ; \square-$ maximum concentrations of SRP and $(\mathrm{N}+\mathrm{N})$, minimum PP; $\mathrm{O}-$ minimum concentrations of SRP and $(\mathrm{N}+\mathrm{N})$, minimum PP; $\diamond-$ minimum concentrations of SRP and $(\mathrm{N}+\mathrm{N})$, maximum PP. not operate according to the Redfield model alone. If the excess SRP in the mixed layer is to be removed by photosynthetic activities, additional sources of combined nitrogen will be required.

\subsubsection{Steady state $(N+N)$ and $S R P$ maintained by nitrogen fixation}

If both $(\mathrm{N}+\mathrm{N})$ and SRP are assumed to be at a steady state in the mixed layer and the need for the additional combined nitrogen is met by nitrogen fixation, then, the mass balance equation for SRP and $(\mathrm{N}+\mathrm{N})$ in the mixed layer would be

$$
\begin{aligned}
& \partial\left(P_{\mathrm{s}} V_{\mathrm{s}}\right) / \partial t=0=E\left(P_{\mathrm{d}}-P_{\mathrm{s}}\right)-\operatorname{PP} r_{\mathrm{p}}, \\
& \therefore \quad E=\left(\operatorname{PP} r_{\mathrm{p}}\right) /\left(P_{\mathrm{d}}-P_{\mathrm{s}}\right), \\
& \partial\left(N_{\mathrm{s}} V_{\mathrm{s}}\right) / \partial t=0=E\left(N_{\mathrm{d}}-N_{\mathrm{s}}\right)-\operatorname{PP} r_{\mathrm{n}}+N_{\mathrm{f}},
\end{aligned}
$$

where $N_{\mathrm{f}}$, in mol- $\mathrm{Nm}^{-2} \mathrm{yr}^{-1}$, is the input flux of combined nitrogen to the mixed layer by nitrogen fixation. By substituting Eq. (6') into Eq. (7),

$$
\begin{aligned}
& \left(\mathrm{PP} r_{\mathrm{p}}\right)\left(N_{\mathrm{d}}-N_{\mathrm{s}}\right) /\left(P_{\mathrm{d}}-P_{\mathrm{s}}\right)-\mathrm{PP} r_{\mathrm{n}}+N_{\mathrm{f}}=0, \\
& \therefore \quad N_{\mathrm{f}}=\left(\operatorname{PP} r_{\mathrm{n}}\right)\left\{1-\left[\left(N_{\mathrm{d}}-N_{\mathrm{s}}\right) /\left(P_{\mathrm{d}}-P_{\mathrm{s}}\right)\right] /\left(r_{\mathrm{n}} / r_{\mathrm{p}}\right)\right\} .
\end{aligned}
$$

Since $N_{\mathrm{d}} \gg N_{\mathrm{s}}, P_{\mathrm{d}} \gg P_{\mathrm{s}}$ and $r_{\mathrm{n}} / r_{\mathrm{p}}=r$,

$N_{\mathrm{f}}=\left(\mathrm{PP} r_{\mathrm{n}}\right)\left[1-\left(N_{\mathrm{d}} / P_{\mathrm{d}}\right) / r\right]$.

Again, $r_{\mathrm{n}}$ is set by the Redfield stoichiometry as $16 / 106$ mol-N mol- $\mathrm{C}^{-1}$ and PP is allowed to vary between 100 and $150 \mathrm{~g}-\mathrm{Cm}^{-2} \mathrm{yr}^{-1}$. The Tropical Water is the subsurface water that is assumed to be mixing with the water in the mixed layer, so that $\left(N_{\mathrm{d}} /\right.$ $P_{\mathrm{d}}$ ) is equal to $14.3 \mu \mathrm{M} \mu \mathrm{M}^{-1}$ and it is allowed to vary between 14 and $15.5 \mu \mathrm{M} \mu \mathrm{M}^{-1}$. Then, the minimum and maximum $N_{\mathrm{f}}$ can be estimated to be 0.04 and $0.24 \mathrm{~mol}-\mathrm{N} \mathrm{m}^{-2} \mathrm{yr}^{-1}$. Supplying this additional amount of combined nitrogen to the mixed layer by atmospheric deposition is not a viable alternative. The atmospheric deposition of combined nitrogen to the SCS has been estimated to be 0.009 mol- $\mathrm{N} \mathrm{m}^{-2} \mathrm{yr}^{-1}$ (Chen et al., 2002). This value is less than a quarter of the minimum $N_{\mathrm{f}}$ and represents the maximum contribution from atmospheric deposition. Any phosphorus that is deposited together with the combined nitrogen will reduce the amount of combined nitrogen that may be used in the mixed layer to remove the excess SRP. Furthermore, an atmospheric source of combined nitrogen would still result in the formation of organic matter with a Redfield N:P molar ratio of 16:1. The remineralization of this organic matter cannot account for the elevated $(\mathrm{N}+\mathrm{N})$ :SRP, up to 
$>16$, and low $\delta^{15} \mathrm{~N}$ in $(\mathrm{N}+\mathrm{N}), \sim 4 \%$ o (Wong et al., 2002), found in the upper nutricline. Thus, it appears unlikely that atmospheric deposition can provide enough combined nitrogen to keep SRP at a steady state in the mixed layer. If the needed amount of additional combined nitrogen is supplied by nitrogen fixation and the combined nitrogen formed is then incorporated into the carbon cycle to form organic matter by phytoplankton activities in general with a nitrogen to carbon ratio of $16 / 106 \mathrm{~mol} \mathrm{~mol}^{-1}$, then the required contribution of nitrogen fixation to net primary production for maintaining a steady state in $(\mathrm{N}+\mathrm{N})$ and SRP in the mixed layer would range between $3 \%$ and $13 \%$. These values, on the one hand, are not insignificant, especially relative to new production, which is on the order of $20 \%$ of net primary production in oligotrophic waters (Eppley, 1989; Falkowski et al., 1998). Based on direct observations, Chen (2005) reported $f$-ratios ranging from 0.14 in the summer to 0.47 in the winter in the northern SCS between 2000 and 2003. On the other hand, these contributions of nitrogen fixation to net primary production are not unreasonably large. Thus, a significant contribution from nitrogen fixation is consistent with the observed distributions of $(\mathrm{N}+\mathrm{N})$ and SRP at the SEATS station. Nevertheless, Chen (2005) did not find a significant number of the traditionally recognized nitrogen fixers, Richelia intracellularis and Trichodesmium spp., in seven seasonal cruises to the northern SCS. This is a paradox that needs to be resolved. It should be noted that data from individual cruises of days in duration, as in Chen's study, and the distributions of the nutrients in the water column, as in this study, capture signals integrating over significantly different time-scales. Furthermore, recent studies (Zehr et al., 1998) also found that, aside from Richelia intracellularis and Trichodesmium spp., other organisms that possess the potential to carry out nitrogen fixation are present in the oceans. Recent observations suggest that such organisms may be present in the northern SCS (Y. Chen, private communication).

\section{Conclusions}

The concentrations of $(\mathrm{N}+\mathrm{N})$ and SRP varied according to a consistent seasonal pattern in the mixed layer at the SEATS station. Concentrations hovered around the detections limits for most of the year and became elevated to readily detectable levels in the winter. The molar ratio of $(\mathrm{N}+\mathrm{N}) / \mathrm{SRP}$ in the deep water, at 13.6, was conspicuously lower than the Redfield ratio of 16 . As a result, the input of nutrients from the deep water by vertical mixing alone could not account for the observed temporal pattern in the concentrations of $(\mathrm{N}+\mathrm{N})$ and SRP. In fact, it would result in a deficit in combined nitrogen, which would then lead to a rapid accumulation of SRP in the mixed layer. Elevated $(\mathrm{N}+\mathrm{N}) / \mathrm{P}$ and $\mathrm{N}^{*}$, even exceeding $16 \mu \mathrm{M} \mu \mathrm{M}^{-1}$ and $2 \mu \mathrm{M}$, respectively, could be found in the upper nitricline and they are indicative of the nitrification of nitrogen-rich organic particles. The variations in $(\mathrm{N}+\mathrm{N}) / \mathrm{P}$ and $\mathrm{N}^{*}$ in a shallow water mass, the Tropical Water, indicate that higher values were found between fall and early spring, when the deposition of atmospheric dusts is expected to be high. This is consistent with the enhancement of nitrogen fixation by the availability of iron through dust depositions. If nitrogen fixation was indeed the source of the additional combined nitrogen to the mixed layer, it would support $3-13 \%$ of the net primary production in the northern South China Sea.

\section{Acknowledgments}

The Southeast Asian Time-series Study (SEATS) and Wong's stay at the National Center for Ocean Research (NCOR) as a visiting scientist at various times during the preparation of this manuscript were supported by the National Science Council, Taiwan through NCOR. The assistance of Y-H. Li, F-K. Shiah, C-C. Chen, B-S. Lee, S.C. Kao, K.K. Liu, C.S. Liu, the technical support personnel at NCOR and the captain and the crew of R/V Ocean Researcher I and Ocean Researcher III during various phases of the planning and implementation of the SEATS science plan is deeply appreciated. This is NCOR contribution no. 106.

\section{References}

Anderson, L.A., Sarmiento, J.L., 1994. Redfield ratios of remineralization determined by nutrient data analysis. Global Biogeochemical Cycles 8, 65-80.

Capone, D.G., Zehr, J.P., Paerl, H.W., Bergman, B., Carpenter, F.J., 1997. Trichodesmium, a globally significant marine cyanobacterium. Science 276, 1221-1229.

Chao, S.Y., Shaw, P.T., Wu, S.Y., 1996a. Deep water ventilation in the South China Sea. Deep-Sea Research I 43, 445-466.

Chao, S.-Y., Shaw, P.-T., Wu, S.Y., 1996b. El Niño modulation of the South China Sea circulation. Progress in Oceanography $38,51-93$. 
Chen, C.-T.A., Wang, S.-L., Wang, B.-J., Pai, S.-C., 2001. Nitrogen budgets for the South China Sea basin. Marine Chemistry 75, 281-300.

Chen, Y.-L.L., 2005. Spatial and seasonal variations of nitratebased new production and primary production in the South China Sea. Deep-Sea Research I 52, 319-340.

Codispoti, L.A., Christensen, J.P., 1985. Nitrification, denitrification and nitrous oxide cycling in the Eastern Tropical South Pacific Ocean. Marine Chemistry 16, 277-300.

Deutsch, S., Gruber, N., Key, R.M., Sarmiento, J.L., Ganachaud, A., 2001. Denitritrification and $\mathrm{N}_{2}$ fixation in the Pacific Ocean. Global Biogeochemical Cycles 15, 483-506.

Duce, R.A., Tinsdale, N.W., 1991. Atmospheric transport of iron and its deposition in the ocean. Limnology and Oceanography $36,1715-1726$.

Eppley, R.W., 1989. New production: history, methods, problems. In: Berger, W.H., Smetacek, V.S., Wefer, G. (Eds.), Productivity of the Ocean: Present and Past. Wiley, New York, pp. 85-97.

Falkowski, P.G., Barber, R.T., Smetacek, V., 1998. Biogeochemical controls and feedbacks on ocean primary production. Science 281, 200-206.

Fanning, K.A., 1992. Nutrient provinces in the sea: concentration ratios, reaction rate ratios, and ideal covariation. Journal of Geophysical Research 97, 5693-5712.

Gong, G.C., Liu, K.K., Liu, C.T., Pai, S.C., 1992. The chemical hydrography of the South China Sea west of Luzon and a comparison with the West Philippine Sea. Terrestrial, Atmospheric and Oceanic Sciences 3, 587-602.

Gruber, N., Sarmiento, J.L., 1997. Global patterns of marine nitrogen fixation and denitrification. Global Biogeochemical Cycles 11, 235-266.

Heinrich, A.K., 1962. The life histories of plankton animals and seasonal cycles of plankton communities in the oceans. Journal du Conseil Internationale pour Exploration de la Mer 27, 15-24.

Hung, J.-J., Wang, S.-M., Chen, Y.-L., 2007. Biogeochemical controls on distributions and fluxes of dissolved and particulate organic carbon in the Northern South China Sea Deep-Sea Research II, this issue [doi:10.1016/ j.dsr2.2007.05.006].

Husar, R.B., Prospero, J.M., L.L. Stowe, L.L., 1997. Characterization of tropospheric aerosols over the oceans with the NOAA advanced very high resolution radiometer optical thickness operational product. Journal of Geophysical Research 102, 16889-16909.

Karl, D.M., Lukas, R., 1996. The Hawaii Ocean Time-series (HOT) program: background, rationale and field implementation. Deep-Sea Research II 43 (2-3), 129-156.

Karl, D.M., Letelier, R., Hebel, D.V., Bird, D.F., Winn, C.D., 1992. Trichodesmium blooms and new production in the North Pacific gyre. In: Carpenter, E.J. (Ed.), Marine Pelagic Cyanobacteria: Trichodesmium and other diazotrophs. Kluwer Academics, Norwell, MA, pp. 219-237.

Karl, D.M., Christian, J.R., Dore, J.E., Hebel, D.V., Letelier, R.M., Tupas, L.M., Winn, C.D., 1996. Seasonal and interannual variability in primary production and particle flux at Station ALOHA. Deep-Sea Research II 43 (2-3), $539-568$.

Karl, D.M., Letelier, R., Tupas, L., Dore, J., Christian, J., Hebel, D., 1997. The role of nitrogen fixation in biogeochemical cycling in the subtropical North Pacific Ocean. Nature 388, 533-538.

Karl, D.M., Björkmann, K.M., Core, J.E., Kujieki, L., Hebel, D.V., Houlihan, T., Letelier, R.M., Tupas, L.M., 2001. Ecological nitrogen-to phosphorus stoichiometry at station ALOHA. Deep-Sea Research II 48, 1529-1566.

Lin, I.I., Liu, W.T., Wu, C.-C., Wong, G.T.F., Hu, C., Chen, Z., Liang, W.-D., Yang, Y., Liu, K.K., 2003. New evidence for enhanced ocean primary production triggered by tropical cyclone. Geophysical Research Letters 30, 1718, doi:10.1029/ 2003 GL017141.

Lin, I.-I., Chen, J.-P., Wong, G.T.F., Huang, C.-W., Lien, C.-C., 2007. Aerosol input to the South China Sea: Results from the MODerate resolution imaging spectro-radiometer, the Quick Scatterometer, and the measurements of pollution in the troposphere sensor. Deep-Sea Research II, this issue [doi:10.1016/j.dsr2.2007.05.013].

Liu, K.-K., Chao, S.-Y., Shaw, P.-T., Gong, G.-C., Chen, C.-C., Tang, T.-Y., 2002. Monsoon-forced chlorophyll distribution and primary production in the South China Sea: observations and a numerical study. Deep-Sea Research I 49, 1387-1412.

Liu, K.-K., Kao, S.-J., Hu, H.-C., Chou, W.-C., Hung, G.-W., Tseng, C.-M., 2007. Carbon isotopic composition of suspended and sinking particulate organic matter in the northern South China Sea-from production to deposition. Deep-Sea Research II, this issue [doi:10.1016/j.dsr2.2007.05.010].

Merrill, J.T., Uematsu, M., Bleck, R., 1989. Meteorological analysis of long range transport of mineral aerosols over the North Pacific. Journal of Geophysical Research 94, 8584-8598.

Pai, S.-C., Yang, C.-C., Riley, J.P., 1990. Formation kinetics of the pink azo dye in the determination of nitrite in natural waters. Analytica Chimica Acta 232, 345-349.

Redfield, A.C., Ketchum, B.H., Richards, F.A., 1963. The influence of organisms on the composition of sea-water. In: Hill, M.N. (Ed.), The Sea, vol. 2. Interscience, New York, pp. 26-77.

Shaw, P.-T., Chao, S.-Y., Liu, K.-K., Pai, S.-C., Liu, C.-T., 1996. Water upwelling off Luzon in the northeastern South China Sea. Journal of Geophysical Research 101, 16435-16448.

Strickland, J.D.H., Parsons, T.R., 1972. A Practical Handbook of Seawater Analysis, Bulletin 167, second ed. Fisheries Research Board of Canada, Ottawa.

Tseng, C.-M., Wong, G.T.F., Lin, I.-I., Wu, C.-R., Liu, K.-K., 2005. A unique seasonal pattern in phytoplankton biomass in low-latitude waters in the South China Sea. Geophysical Research Letters 32, L08608.

Ward, B.B., 1987. Nitrogen transformation in the Southern California bight. Deep-Sea Research 34, 785-805.

Wong, G.T.F., Chung, S.-W., Shiah, F.-K., Chen, C.-C., Wen, L.-S., Liu, K.-K., 2002. Nitrate anomaly in the upper nutricline in the northern South China Sea-evidence for nitrogen fixation. Geophysical Research Letters 29, 2097.

Wu, J., Chung, S.-W., Wen, L.-S., Liu, K.-K., Chen, Y.-1.L., Chen, H.-Y., Karl, D.M., 2003. Dissolved inorganic phosphorus, dissolved iron and Trichodesmium in the oligotrophic South China Sea. Global Biogeochemical Cycles 17 (1), 1008.

Zehr, J.P., Mellon, M.J., Zani, S., 1998. New nitrogen fixing microorganisms detected in oligotrophic oceans by the amplification of nitrogenase $($ nif $\mathrm{H})$ genes. Applied Environmental Microbiology 64, 3444-3450. 